\title{
Unsupervised drill core pseudo-log generation in raw and filtered data, a case study in the Rio Salitre greenstone belt, São Francisco Craton, Brazil
}

Guilherme Ferreira da Silva ( $\square$ guilherme.ferreira@cprm.gov.br )

Geological Survey of Brazil (CPRM) https://orcid.org/0000-0002-3675-7289

João Henrique Larizzatti

Geological Survey of Brazil (CPRM)

Anderson Dourado Rodrigues da Silva

Geological Survey of Brazil (CPRM)

Carina Graciniana Lopes

Geological Survey of Brazil (CPRM)

Evandro Luiz Klein

Geological Survey of Brazil (CPRM)

Kotaro Uchigasaki

Geological Survey of Brazil (CPRM)

\section{Research Article}

Keywords: K-means, Model-Based Clustering, Unsupervised Learning, Portable X-Ray Fluorescence

Posted Date: September 7th, 2021

DOI: https://doi.org/10.21203/rs.3.rs-871865/v1

License: (1) This work is licensed under a Creative Commons Attribution 4.0 International License. Read Full License

Version of Record: A version of this preprint was published at Journal of Geochemical Exploration on January 1st, 2022. See the published version at https://doi.org/10.1016/j.gexplo.2021.106885. 
1 Unsupervised drill core pseudo-log generation in raw and filtered data, a case

2 study in the Rio Salitre greenstone belt, São Francisco Craton, Brazil

3 Guilherme Ferreira da Silva (Corresponding author)

4 Directory of Geology and Mineral Resources, Geological Survey of Brazil - CPRM,

5 ORCiD https://orcid.org/0000-0002-3675-7289

6 guilherme.ferreira@cprm.gov.br

7 João Henrique Larizzatti

8 Directory of Geology and Mineral Resources, Geological Survey of Brazil - CPRM,

9 ORCiD https://orcid.org/0000-0002-6778-4132

10 joao.larizzatti@cprm.gov.br

11 Anderson Dourado Rodrigues da Silva

12 Directory of Geology and Mineral Resources, Geological Survey of Brazil - CPRM,

13 ORCiD https://orcid.org/0000-0001-9841-4225

14 anderson.rodrigues@cprm.gov.br

15 Carina Graciniana Lopes

16 Directory of Geology and Mineral Resources, Geological Survey of Brazil - CPRM,

17 ORCiD https://orcid.org/0000-0001-8150-3029

18 carina.lopes@.cprm.gov.br

19 Evandro Luiz Klein

20 Directory of Geology and Mineral Resources, Geological Survey of Brazil - CPRM,

21 ORCiD https://orcid.org/0000-0003-4598-9249

22 evandro.klein@cprm.gov.br

23 Kotaro Uchigasaki

24 Directory of Geology and Mineral Resources, Geological Survey of Brazil - CPRM,

25 ORCiD https://orcid.org/0000-0001-9199-6322

26 kotaro.uchigasaki@.cprm.gov.br 


\section{Abstract}

28 We use in situ portable X-Ray Fluorescence data acquired in sawn drill core samples of rocks

29 from the Sabiá prospect, at the Rio Salitre greenstone belt, São Francisco Craton Brazil, for 30 pseudo-log automatic generation through running unsupervised learning models to group

31 distinct lithotypes. We tested the K-means and Model-Based Cluster (MBC) algorithms and compared their performance in the raw and filtered data with a manual macroscopic log description. From the initial 47 available elements, 20 variables were selected for modeling following the criteria of presenting at least $95 \%$ of uncensored values. Additionally, we performed a Shapiro-Wilk test that confirmed a non-parametric distribution by verifying the Pvalue attribute less than the 5\% significance level. We also checked if the dataset's distribution was statistically equivalent to the duplicates with the assistance of a Kruskal-Walis test, which would confirm the representativity power of the measurements at the same $5 \%$ significance level. After this step, the pseudo-log models were created based on reduced dimension data,

40 compressed by a centered Principal Component Analysis with data rescaled by its range.

41 Concerning to reduce the high-frequency noise in the selected features, we employed an 42 exponential weighted moving average filter with a window of five samples. By the analysis of the Average Silhouette Width on sample space, the optimum number for K-means was fixed in

44 two, and then the first models were generated for raw and filtered data. From the MBC 45 perspective, the sample space is interpreted as a finite mixture of groups with distinct Gaussian 46 probability distribution. The number of clusters is defined by the analysis of the Bayesian 47 Information Criteria (BIC), where several models are tested, and the one in the first local maximum defines the number of groups and the type of probabilistic model in the simulation.

49 For the data used in this work, the optimum group number for $\mathrm{MBC}$ is four, and the probabilistic

50 model type determined by the BIC is elliptical with equal volume, shape, and orientation. Thus,

51 Model-Based Cluster has detected four different cluster groups with almost the same 
52 representativity for the two drill cores' samples. All K-means and MBC models were able to 53 detect changes in lithotypes not described in the manual log. On the other hand, one lithotype 54 described by the experts was not detected by this methodology in any attempt. It was needed a 55 detailed investigation with thin section descriptions to determine the cause of this response. 56 Finally, compared with the manual log description, it is notable that the models built on filtered 57 data have better performance than those generated on raw data, and the MBC filtered model 58 had better performance than the others. Hence, this multivariate approach allied to filtering the

59 data with a moving average transformation can be a tool of great help during several stages of 60 mineral exploration, either in the creation of pseudo-log models prior the description of the drill 61 core samples or in the data validation stage, when it is necessary to standardize several 62 descriptions made by different professionals.

63

64 KEYWORDS: K-means, Model-Based Clustering, Unsupervised Learning, Portable X-Ray 65 Fluorescence 66 
68 The "data-rich paradigm" is already a reality in mineral exploration. This scenario can be found

69 in several segments of the mineral industry, such as airborne geophysics, exploratory

70 geochemical surveys, mineral resources, and reserves analyses evaluation, studies of physical

71 properties of the rock, mechanical assays of mine engineering, ore grade control, and

environmental monitoring, among many other study branches associated with various stages in

the mineral research. Moreover, some government entities (Agencies and Geological Surveys) also provide valuable data for the mineral industry, increasing the available volume of information. In this data-dominated scenario, fast, consistent, and reliable analysis is vital for decision making and resource investment.

One of the mineral industry's main challenges in practically all stages of exploration is to manage and integrate information from large data sets. Log description is a qualitative analysis based on the geologist's experience, and sometimes challenging to match together, mainly when several professionals describe a large volume of samples over a long period. Also, the drill core manual interpretation can be very time-consuming and challenging, especially when integrating into the analysis of multiple variables (Hill et al., 2020).

Despite some limitations, portable X-Ray Fluorescence analysis (pXRF) can be useful in

84 numerous scenarios, whether to increase the spatial resolution of laboratory data or to assist in real-time or near-real-time support for operational decisions in drill core management (Fisher et al., 2014). The significant advantages of the pXRF over conventional laboratory analysis are the speed of data collection and the low cost of the analyses (Le Vaillant et al., 2014), which permits the compilation of a high amount of spatially representative information.

89 Machine Learning Algorithms (MLA) has proved to be a useful tool in managing geological

90 data in several instances. Some of the most notable cases of MLA applied to geosciences focus on a diverse range of topics, such as prediction of hydrothermal alteration, automatic detection 
92 of basement rocks in drill-hole, refining lithological mapping using airborne geophysics, and

93 identifying mineral prospectivity by the integration of regional data (Bérubé et al., 2018; Costa

94 et al., 2019; Hill and Uvarova, 2018; Kuhn et al., 2018; Rodriguez-Galiano et al., 2015; Wedge

95 et al., 2019).

96 In this work, we present an approach to assist the drill core management with a fast, consistent,

97 and highly reproducible methodology based on open-source code and data already acquired,

98 which sometimes represents a challenge due to survey issues and/or the high number of

99 geochemical features. For this purpose, we employed unsupervised Machine Learning methods

100 in portable X-Ray Fluorescence data of drill core rock samples to generate pseudo-log. The

101 term pseudo-log is used here in the sense of automatic classification of the rock samples stacked

102 in the same order of the drill core depth and not validated by a specialist. We tested and

103 compared the performance of two standard clustering algorithms, K-means, and the MBC, in

104 raw and transformed data, filtered by the EWMA convolution. The clustering models were

105 performed in results obtained from two drill cores near the sulfide-rich Sabiá prospect (Ribeiro

106 et al., 1993), in the Rio Salitre greenstone belt (RSGB), São Francisco Craton, located in Bahia,

107 northeastern Brazil (Figure 1). 


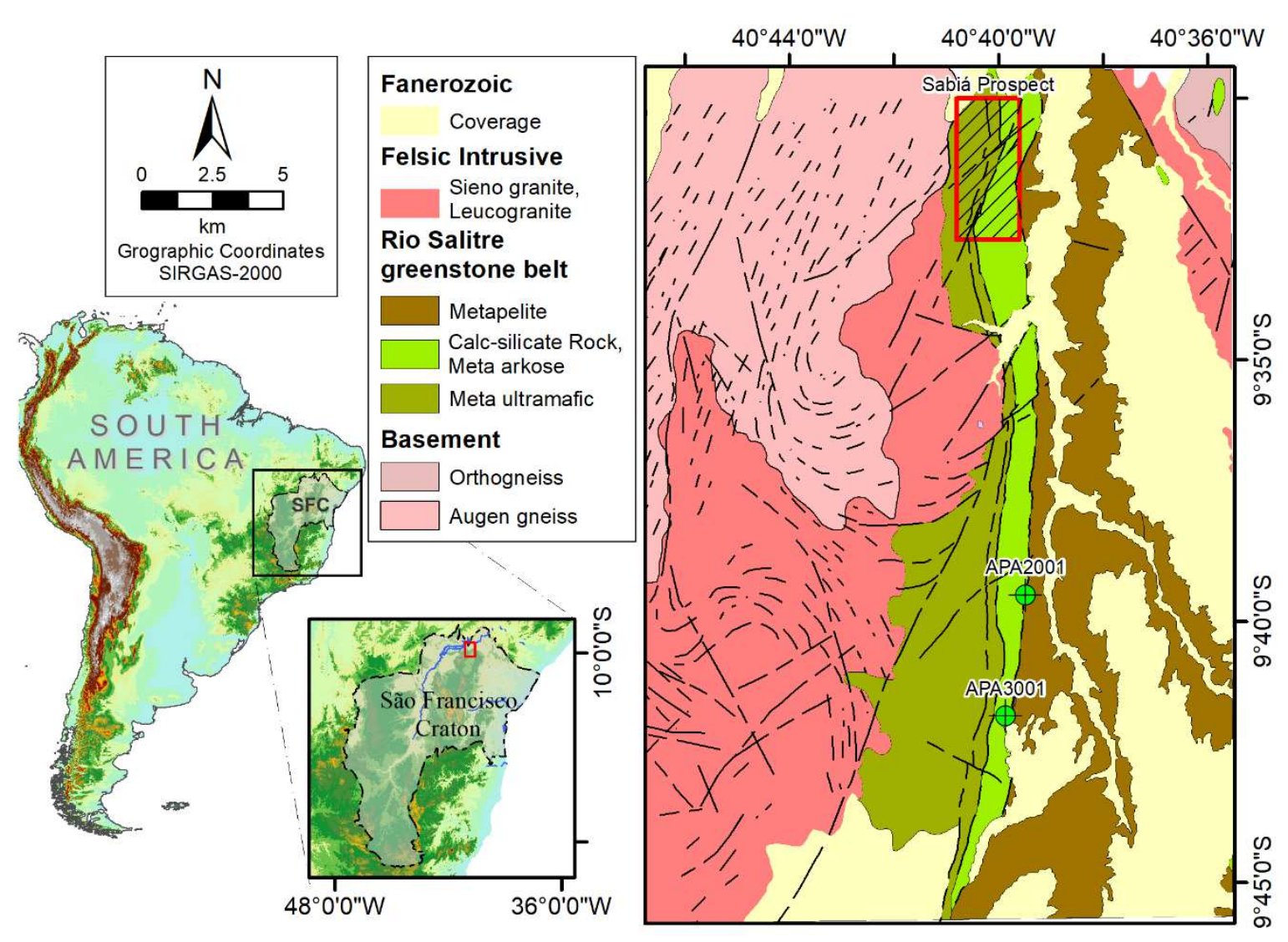

Figure 1: Location of the São Francisco Craton and simplified geological map of the Rio Salitre

110 greenstone belt, showing the approximate location of the Sabiá prospect.

\section{$111 \quad$ 1.1. Geological setting}

112 The RSGB is located in the São Francisco Craton (SFC), a major geotectonic unit of the South

113 American platform, placed in the southeast and northeast regions of Brazil, and stabilized

114 during the Neoproterozoic Brasiliano cycle of orogenies. (Almeida et al., 1981; Heilbron et al.,

115 2017). The SFC comprises a large number of Archean to Paleoproterozoic TTG-gneisses,

116 granitoids, and greenstone belts, which consist of various sialic units, some of them named

117 Gavião, Serrinha, and Jequié blocks (Alkmim and Martins-Neto, 2012; Alkmin et al., 1993;

118 Barbosa and Barbosa, 2017; Barbosa and Sabaté, 2004; Barbosa, 2012; Cordani et al., 1992;

119 Oliveira et al., 2010; Teixeira et al., 2017, 1996). The Gavião block, north of the São Francisco

120 Craton, comprises a variety of TTG, granitoids, migmatites, and greenstone belt-like 
121 metavolcano-sedimentary associations (e.g., Rio Salitre, Brumado, Boquira, and Riacho de

122 Santana, Barbosa, 2012).

123 The RSGB is a Paleoproterozoic metavolcano-sedimentary sequence located in the

124 northernmost portion of the Gavião Block (Barbosa and Barbosa, 2017; Garcia, 2017; Teixeira

125 et al., 2017). The Rio Salitre consists of two units, from bottom to top: i) Baixo Vale do Rio

126 Salitre: metapelites, metagraywacke, and meta-arkose, interlayered with mafic-ultramafic and

127 felsic metavolcanic rocks and ii) Sobradinho: composed of banded iron formations, paragneiss,

128 phyllites, mica schists, metabasic and meta-ultrabasic rocks, calc-silicate rock, and quartzites.

129 These units were deformed and metamorphosed at low greenschist facies metamorphic grade.

130 The RSGB has potential for base metals $(\mathrm{Cu}-\mathrm{Pb}-\mathrm{Zn})$ associated with VHMS and orogenic gold 131 type deposits (Barbosa, 2012). Several occurrences of $\mathrm{Cu}-\mathrm{Pb}-\mathrm{Zn}$ have been described in this 132 sequence, highlighting the Sabiá prospect (reserves of 10 million tons of massive sulfide,

133 Ribeiro et al. 1993), presenting pyrite- and pyrrhotite-rich levels in calc-silicate rocks with 134 tremolitization associated with the Sobradinho unit (Angelim, 1997).

\section{$135 \quad$ 1.2. Rock samples}

136 The samples used in this work were collected from two complementary drill cores next to the

137 Sabiá prospect, that intercept all the stratigraphy of the Baixo Vale do Rio Salitre unit. On 138 average, the samples have $15 \mathrm{~cm}$ of length, and one sample was taken from about every 2 139 meters.

140 The described rocks are mostly fine-grained and show similar color and texture. These features 141 make manual logging, an essential task in mineral exploration, complicated and costly.-Despite

142 similarities between the drill cores' lithotypes, we described at least four rocks types: calc143 silicate rocks, carbonaceous phyllites with and without mineralization, metapelites, and 144 metamafic rocks (Figure 2). 
145 The mineralized portions, hosted by carbonaceous phyllites, are characterized by centimetric

146 layers of discordant to concordant massive pyrite (Figure 2 d), associated with locally

147 disseminated sulfides (pyrite and pyrrhotite) and sulfide remobilization in calcite veinlets.

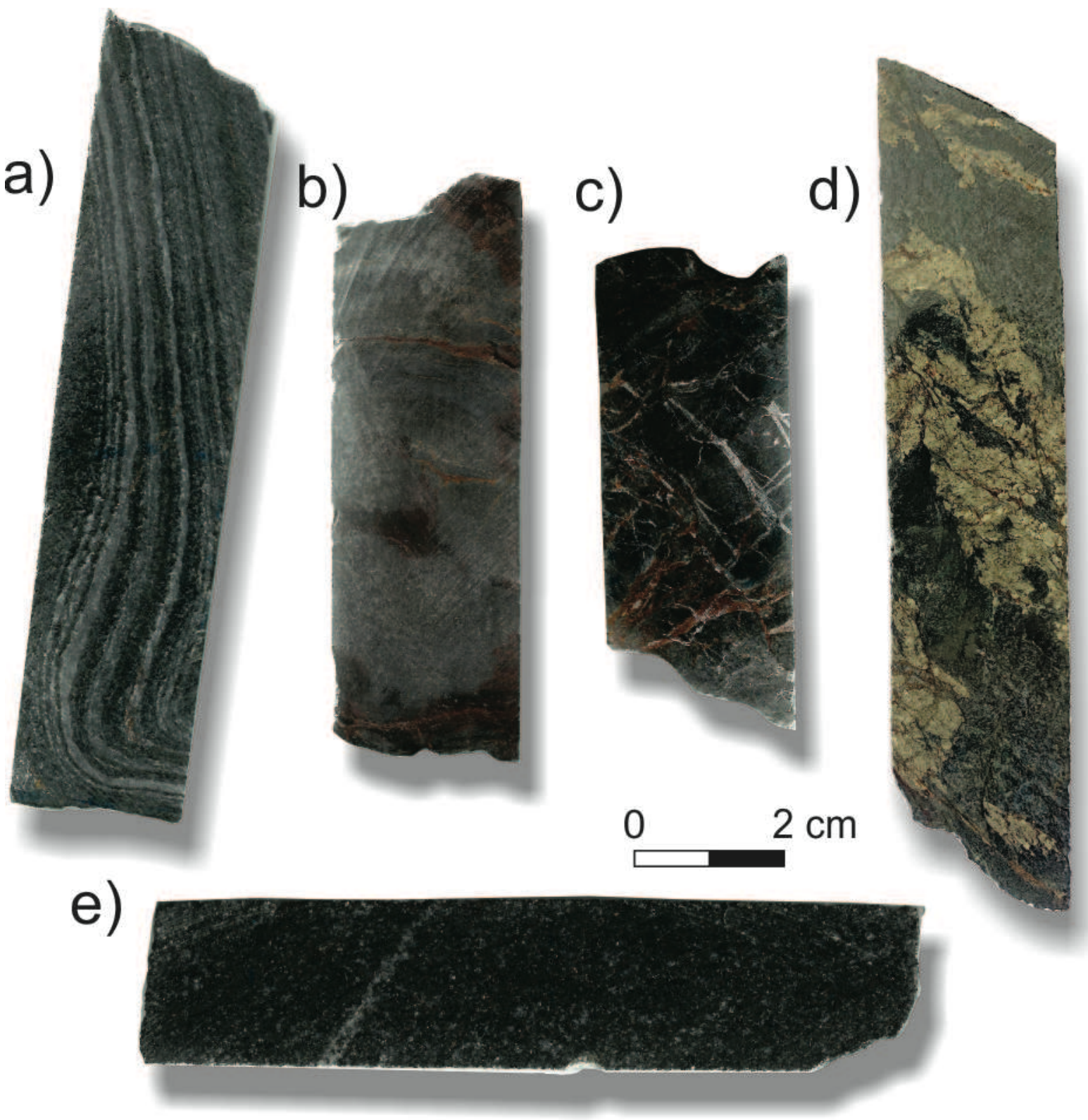

149 Figure 2: Representative rock samples from different lithotypes used in this study: a) calc-silicate rock,

150 b) metapelite, c) carbonaceous phyllite, d) mineralized carbonaceous phyllite, and e) metamafic rock.

\subsection{X-Ray Fluorescence}

The instrument used in this work was a Thermo Scientific Niton XL3t Goldd+ XRF analyzer,

153 with $2 \mathrm{~W}, 50 \mathrm{kV}$ Au anode tube, and a geometrically optimized large area drift detector. The 
instrument offers three methods of analysis, and the method chosen in this work is named

155 "TestAll Geo," indicated when the concentration of interest elements is unknown. "TestAll

156 Geo" is a hybrid mode able to detect several major, minor, and trace elements: Ag, Al, As, Au,

$157 \mathrm{Ba}, \mathrm{Bi}, \mathrm{Ca}, \mathrm{Cd}, \mathrm{Ce}, \mathrm{Cl}, \mathrm{Co}, \mathrm{Cr}, \mathrm{Cs}, \mathrm{Cu}, \mathrm{Fe}, \mathrm{Hf}, \mathrm{Hg}, \mathrm{La}, \mathrm{Mg}, \mathrm{Mn}, \mathrm{Mo}, \mathrm{Nb}, \mathrm{Nd}, \mathrm{Ni}, \mathrm{P}, \mathrm{Pb}, \mathrm{Pd}$,

$158 \mathrm{Pr}, \mathrm{Rb}, \mathrm{Re}, \mathrm{S}, \mathrm{Sb}, \mathrm{Sc}, \mathrm{Se}, \mathrm{Si}, \mathrm{Sn}, \mathrm{Sr}, \mathrm{Ta}, \mathrm{Te}, \mathrm{Th}, \mathrm{Ti}, \mathrm{U}, \mathrm{V}, \mathrm{W}, \mathrm{Y}, \mathrm{Zn}, \mathrm{Zr}$. The instrument was

159 coupled on a stationary test stand during the measurements, where the samples were placed.

160 Each measurement took 120 s, with 60 s of duration for each beam.

161 The measurements were performed on quartered and sawed drill core samples, using the "point

162 and shoot" or in situ assay mode. The QA/QC adopted procedures followed the suggestions of

163 Fisher et al. (2014) and Piercey (2014) and, as the certified material used in this work, are

164 described in Appendix A.

165 Aiming to check the representativeness of information, the second measurement of each sample

166 was collected on another spot. Despite some outlier values for all considered elements, the main

167 distribution is maintained in both first and second analyzed spots (Figure 3). The statistical

168 verification of distribution type and equivalence between data from the first and second spot

169 distributions are presented in Appendix B. 


\section{Boxplot of selected elements}

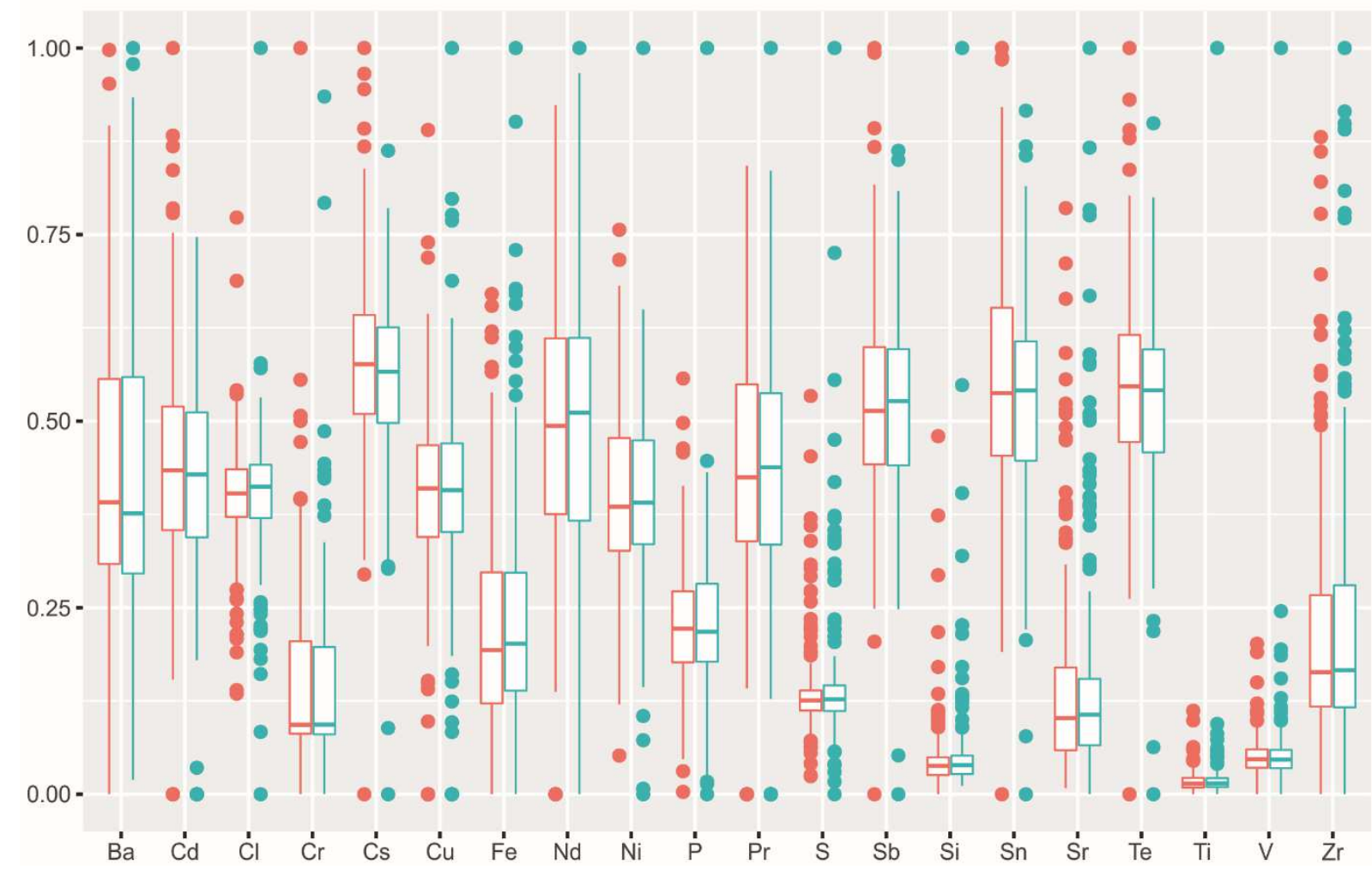

171 Figure 3: Boxplot graphic for selected elements rescaled to a 0-1 distribution and classified by first and 172 second spot analysis

\section{2. Data Preparation}

\subsection{Data management}

175 The bulletins of the X-Ray Fluorescence data were gathered in a single spreadsheet. All

176 procedures of data preparation were performed in the $\mathrm{R}$ environment. The data management

177 step was performed using the concepts of "Tidydata" handling, with the "dplyr" package

178 (Wickham, 2014). The graphical analysis and all statistical diagrams shown in this work were

179 done using the package "ggplot2" (Wickham, 2016).

180 From an initial number of 47 elements, we selected 20 for exploratory data analysis following

181 the proportion of uncensured data. Only variables with at least $95 \%$ of valid results were taken.

182 Then, for the multivariate analysis, all missing values were replaced by half of the lower limit 183 of detection, as suggested by Farnham et al. (2002) and Kwak and Kim (2017). No outliers 
were removed from the data, as outliers can represent some interesting samples in mineralization.

186 Each variable was scaled to values between 0 to 1 regarding its range using a Min-Max Feature

187 scaling. This approach matches the ranges into given values but preserves the original data

188 distribution. The normalization is a mandatory step of data preparation in multivariate analysis

189 because of the variance's regularization, an essential parameter to several statistical procedures

190 and verifications (Grunsky, 2010). The Min-Max Feature Scaling is given as:

$$
y_{(i)}=\frac{x_{(i)}-\min (x)}{\max (x)-\min (x)}
$$

192 where $x_{(i)}=\left(\mathrm{x}_{1}, \ldots, \mathrm{x}_{\mathrm{n}}\right)$, and $y_{(i)}$ is the $i^{\text {th }}$ normalized data.

\subsection{Exponentially Weighted Moving Average Filtering}

194 The Exponentially Weighted Moving Average (EWMA) is a filtering process similar to a lowpass convolution, extensively applied in financial market analysis for anomaly detection, forecasting risk analysis, and pattern prediction in general (Lucas and Zhang, 2016; Mitra et al., 2019; Nakano et al., 2017; Ross et al., 2012).

198 The nature of geological data in drill core samples allows the interpretation that neighbors

199 samples may have a particular correlation. Therefore, the EWMA filtering process is suitable 200 for reducing the high-frequency noise, which can either result from some specificity of a sample 201 (nugget effect) or is a product of accuracy issues of the pXRF analysis.

202 EWMA filtering is described as follows:

$$
E W M A_{x i}=\frac{x_{i}+(1-\alpha) x_{i-1}+\cdots+(1-\alpha)^{n} x_{i-n}}{1+(1-\alpha)+\cdots+(1-\alpha)^{n}}
$$

204 Where $E W M A_{x i}$ is the filtered value for the $x_{i}$ sample, $n$ is the number of neighbors samples 205 considered in the filtering process, and $\alpha$ is the weighting coefficient that decays exponentially 206 from the centered sample in the function of the distance and is defined as: 


$$
\alpha=\frac{2}{n+1}
$$

208 The EWMA filtering has some advantages, such as a fast performance with low computational 209 cost, strong smoothing properties, with the weights of the neighbor's samples automatically 210 given in function of the number of neighbors. EWMA requires the definition of some 211 hyperparameters, adjusted by the interpreter. The more neighbors' values are considered during 212 the filtering process, the smoother the resulting curve. In most cases, when many neighbors are 213 considered, it also adds an offset or lag incrementation to the curve's shape. Furthermore, it may 214 input loss of information as the first $n-1$ samples are lost in the filtering process.

215 For data used in this work, the optimum value of neighbors was defined as five, as there was 216 no visible offset added to data, and the algorithm still performed a considerable smoothing in 217 the pattern of the analyzed curve with minimal data loss (Figure 4). For comparison purposes, 218 filtered and raw data sets were treated separated in most of the further analyses.

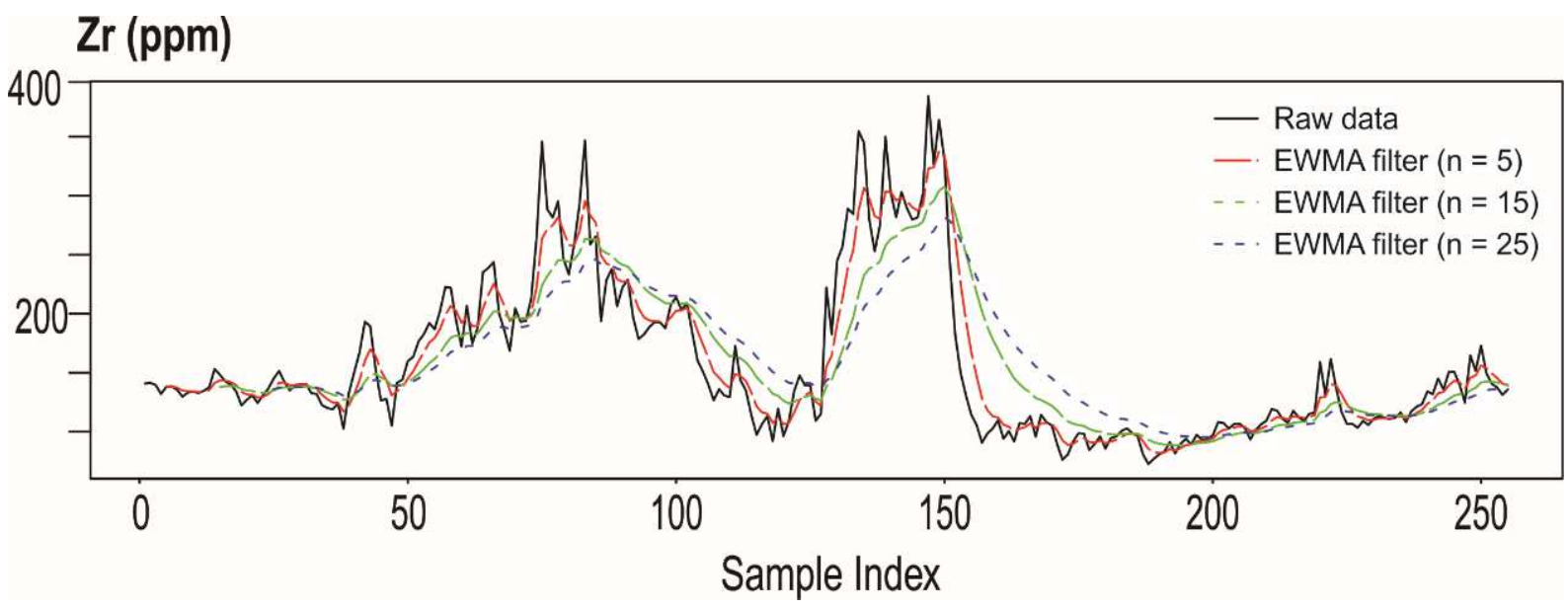

220 Figure 4: concentration of $\mathrm{Zr}(\mathrm{ppm})$ of ranked samples for raw data (black line), filtered data for five 221 (red dashed line), fifteen (green dashed line ), and twenty-five (blue dashed line) neighbors.

222 3. Data Analysis

223

\subsection{Correlation}


224 The Spearman correlation index $(\rho)$ is a rank-based non-parametric correlation of $n$ variables

225 taken by pairs, that measures the capacity of the $i$ rank-ordered values of one variable to predict

226 the rank-ordered values of another.

227 The value of $\rho$ was calculated by the selected elements in the raw and filtered dataset (Figure

228 5). In the two groups of data, it is possible to identify groups of elements that correlate with 229 each other, both with positive and negative correlations. Ba and $\mathrm{Zr}$ correlate with each other 230 and show moderate to strong negative correlation with almost all others. The others groups that 231 show a good correlation is $\mathrm{Nd}, \mathrm{Pr}, \mathrm{Sb}, \mathrm{Sn}, \mathrm{Cd}, \mathrm{Cs}$, and Te with a positive correlation varying 232 from 0.5 to 0.9 and $\mathrm{Cu}, \mathrm{Ni}, \mathrm{Fe}, \mathrm{Cr}, \mathrm{V}$, and $\mathrm{Ti}$ with a weak to strong correlation varying from 2330.3 to 0.8 . By comparing both correlation matrices, it is possible to notice that the elements' 234 relationships tend to be stronger in the filtered data than in the raw data. 


\section{Filtered data}

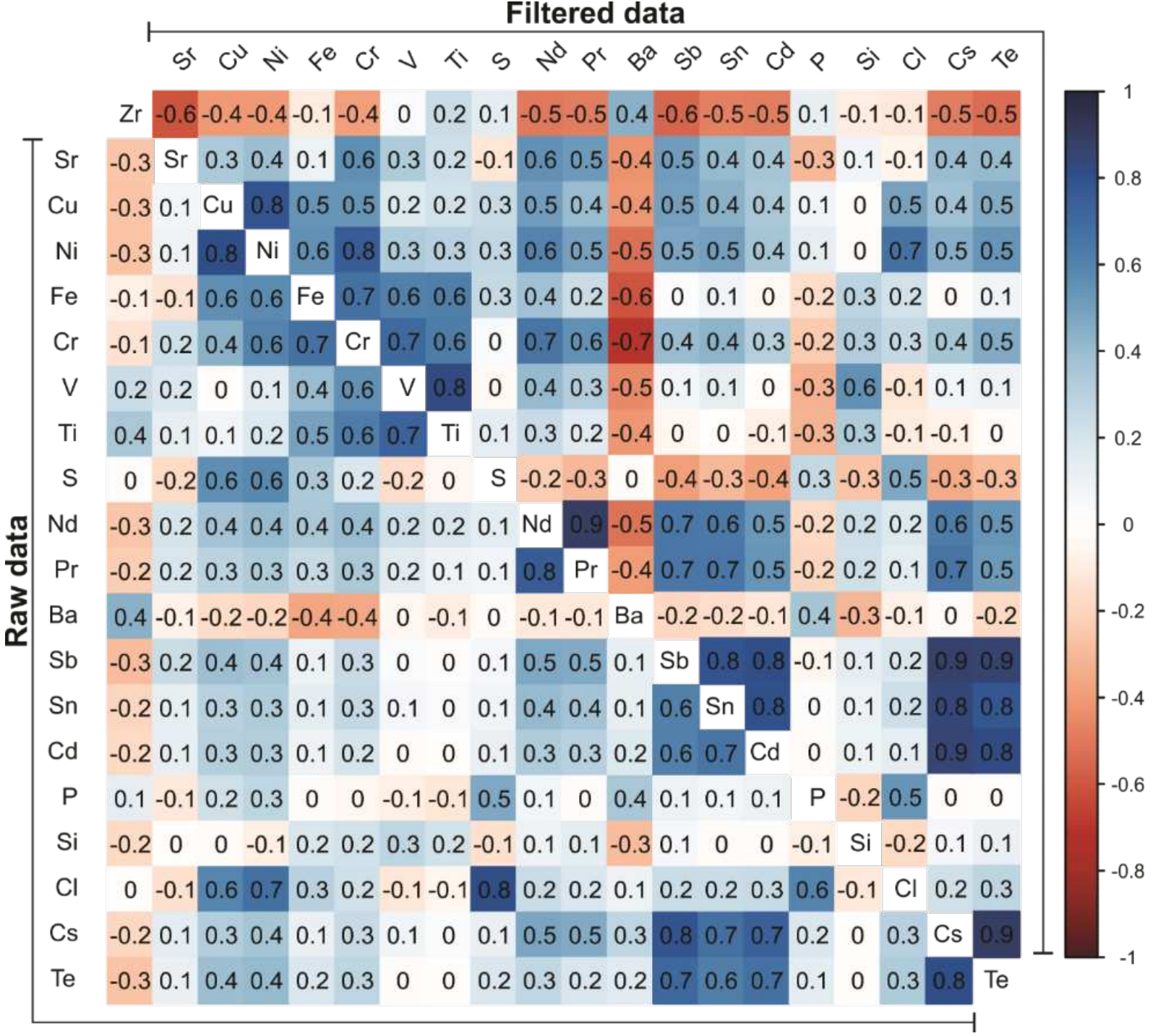

236 Figure 5: Spearman ranked correlogram of the selected elements for filtered (upper triangular matrix) 237 and raw data (lower triangular matrix).

238 All these groups and associations between elements represent the compositional variation of

239 the main constituent minerals of the analyzed lithotypes. In a traditional assessment, the

240 interpreter tries to link these associations to previously known lithotypes. However, due to the

241 high number of analyzed variables, interpretation can become challenging even for the most

242 experienced professionals. 
244 The most common dimensionality reduction method is the Principal Component Analysis

245 (PCA; Grunsky and Arne, 2020). PCA relies on a combination of linear transformations called

246 "basis change" that aims to maximize the data variance on several orthogonal axes, ordered by

247 the first to the last, based on the proportion of explained variance of the dataset. Thus, the first

248 components are often interesting for multivariate analysis, since they typically account for a

249 large proportion of the total variation, as the last components are usually discarded since they

250 may reflect noise rather than the systematic pattern (Forkman et al., 2019). PCA is particularly

251 util before running a cluster analysis because as many clustering methods rely on the "distance

252 concept" (Frey and Dueck, 2007), the PCA's space optimization helps in these processes.

253 For the dataset used in this work, PCA ran on filtered indicates that the filtering process

254 effectively assists on the noise reduction, as the first components explain a considerable amount

255 of data variance, compared to PCA ran on raw data (Figure 6). Thus, the five first components

256 of the filtered data explain $86 \%$ of data variance, while the same number of components

257 explains $76 \%$ of the variance on raw data, making the other 15 components almost negligible

258 in both cases. Taking advantage of dimensionality reduction, we used the PCA transformation

259 in raw and filtered data as input of the Unsupervised Learning models. 
a) Scree plot

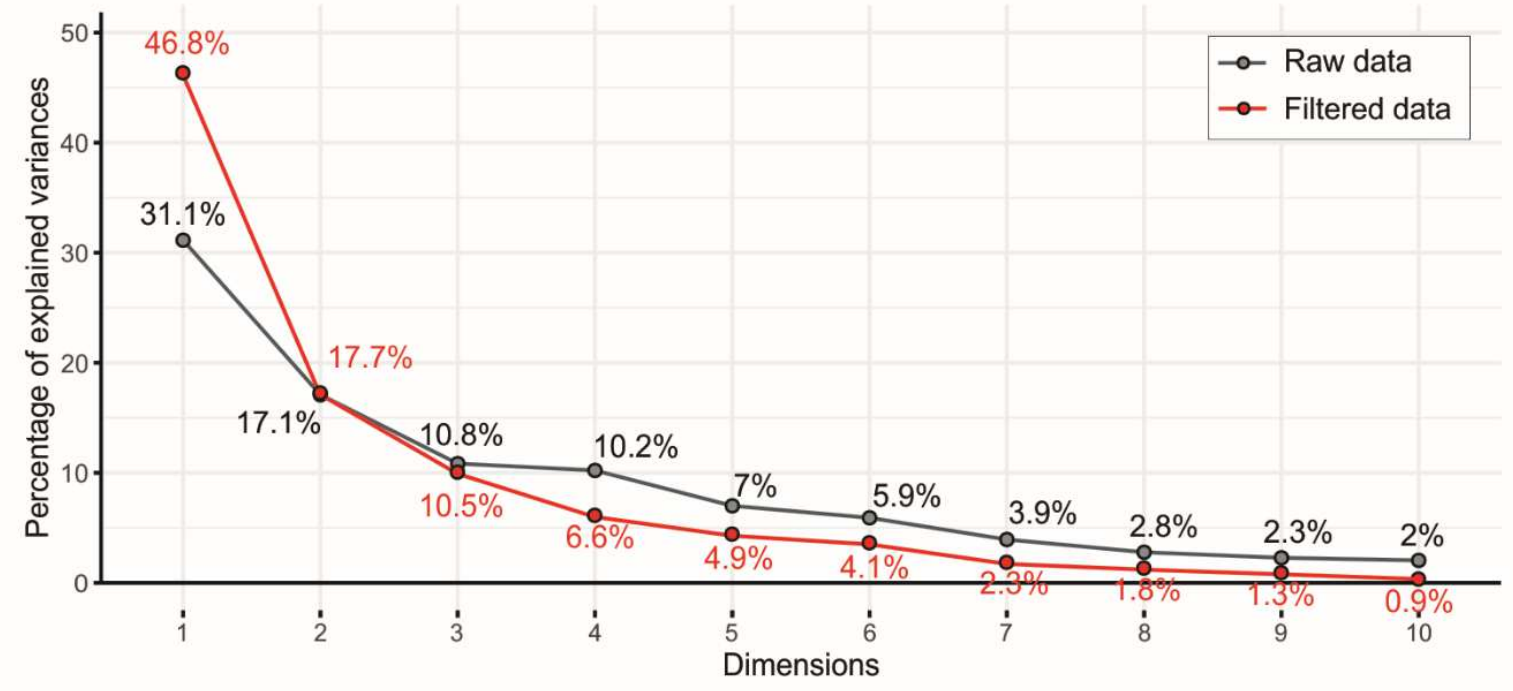

b) PCA (raw data)

c) PCA (filtered data)
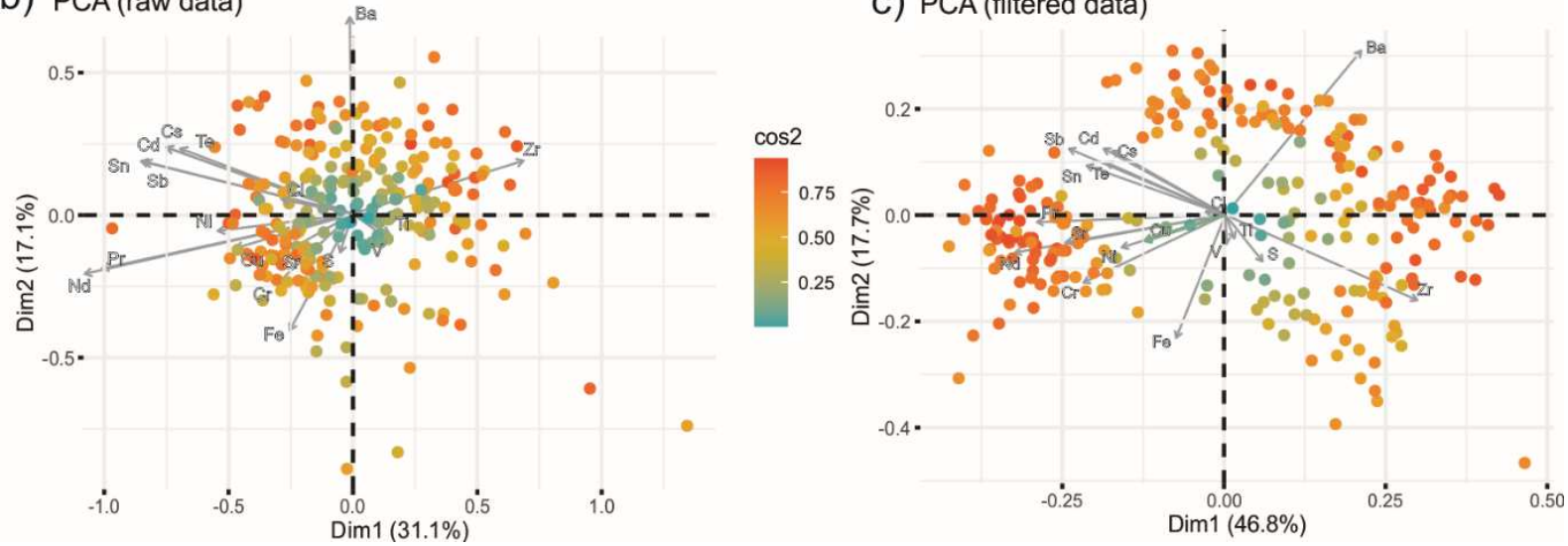

261 Figure 6: PCA of the selected variables: a) Scree plot of the first ten dimensions and the respective

262 percentage of explained variance for raw (grey curve) and filtered data (red curve); b) Individuals and

263 Eigenvectors plot of First and Second Dimensions colored by the $\cos ^{2}$ value for raw and c) for filtered 264 data.

\section{Unsupervised Learning}

\subsection{K-means}

267 K-means is a common unsupervised approach that aims to minimize the dissimilarity between

268 the $i^{\text {th }}$ sample and its respective centroid (Landau and Chis Ster, 2010; Lloyd, 1982). Many

269 algorithms work based on Euclidean Distance, but most of them also permit to change this 270 parameter to an alternative spatial representation. 
271 The algorithm functions by determining which cluster's centroid is closest to each point. Each

272 point is then assigned to its nearest cluster. Each cluster's centroid is recalculated as the

273 arithmetic mean or geometric center of all its assigned points' locations. This process is repeated

274 until no points can be assigned to a closer cluster, or the stopping condition has been reached

275 (Mouton et al., 2020). The algorithm's standard input is the data, the number of iterations, and

276 the number of clusters that cannot be defined automatically for the algorithm.

277 The Silhouette Width $s(i)$ is defined based on the relation between the $i^{\text {th }}$ sample and the

278 distances from the center of the respective cluster and the center of the closest neighbor cluster

279 not containing this sample (Lengyel and Botta-Dukát, 2019), and can be expressed as follows:

$$
s(i)=\frac{b(i)-a(i)}{\max \{a(i), b(i)\}}
$$

281 Where dissimilarity $b(i)$ between the $i^{\text {th }}$ sample and the nearest cluster not containing $i$, and $282 a(i)$ is the same metric between $i$ and the center of the given cluster. Therefore, the Average 283 Silhouette Width is the sum of the respective values of Silhouette Width divided by the number 284 of samples (Lengyel and Botta-Dukát, 2019)

$$
S\left(x_{1}, \ldots, x_{n}\right)=\frac{\sum_{i=1}^{n} s(i)}{n}
$$

286 Hence, for a specific $k$ number of clusters, the one better suitable for the data is the value of $k$ 287 that maximizes $S$.

288 For the data used in this work, the maximum value for the Average Silhouette Width was 289 obtained with $k=2$, value considered for further models of K-means Clustering (Figure 7) 


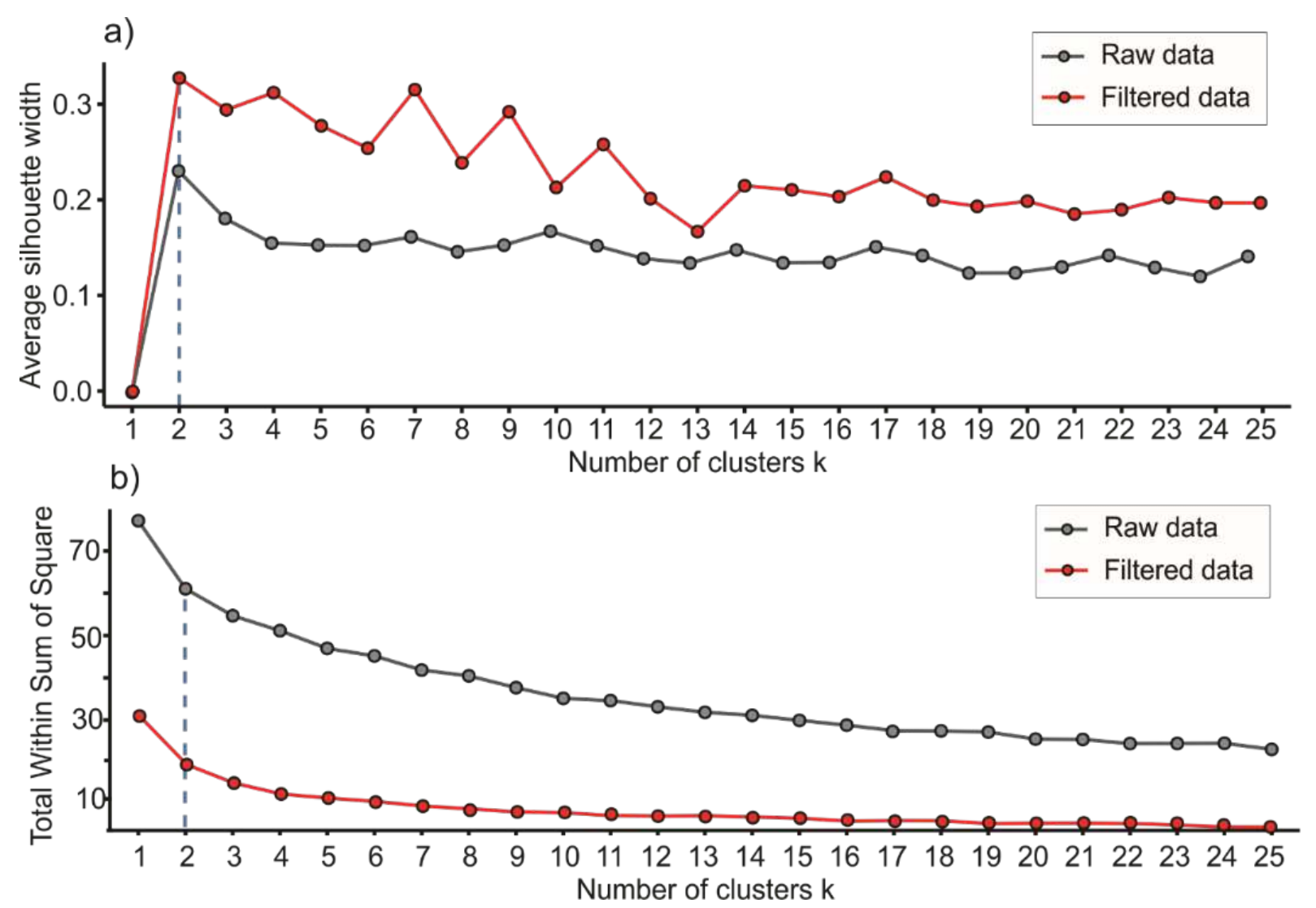

291 Figure 7: Estimates of the optimum number of clusters by a) the Elbow method and b) the Average 292 Silhouette Width

\subsection{Model-Based Clustering}

Unlike K-means, a Model-Based Clustering (MBC) does not require any hyperparameter imputation or prior information about the number of groups or the distributions. In $\mathrm{MBC}$, it is assumed that the data are generated by a mixture of underlying probabilities distributions in

297 which each component represents a different group or cluster (Fraley and Raftery, 2002, 1998;

298 Lai et al., 2018; Landau and Chis Ster, 2010).

299 The data partition is determined by the Expectation-Maximization (EM) for maximum

300 likelihood, with initial values from agglomerative Hierarchical Clustering (Fraley and Raftery, 301 1998). Then, several distribution models are compared using the Bayesian information criterion 302 (BIC) applied to multiple models simultaneously. 
The BIC is based on Bayesian factors, which is the posterior odds for one model against

304 other assuming neither is favored a priori (Fraley \& Raftery, 1998). The BIC is independent of

305 how the different models are built, changing some constraints about the clusters' shape, volume,

306 and orientation. After comparing the possible models through different numbers of clusters,

307 from 1 to $n$, the first local maximum is considered to be the best suitable model (Boehmke and

308 Greenwell, 2019)

309

$$
B I C=\ln (n) k-2 \ln (\hat{L})
$$

310 Where $n$ is the sample size, $k$ is the number of parameters estimated by the model and $\hat{L}$ is

311 the maximized value of the likelihood function (Boehmke and Greenwell, 2019), as follows:

$$
\widehat{L}=p(x \mid \hat{\theta}, M)
$$

313 Where $\mathrm{M}$ is a probabilistic model, $\hat{\theta}$ is the parameters that maximize the likelihood function 314 and $x$ the observational data.

315 The EM algorithm shows that for the filtered data, the suitable number of clusters is four,

316 given by the first local maximum BIC value for the EEE model. This model adjusts a given

317 number of elliptical clusters of equal volume and direction, and a probabilistic model is 318 calculated based on point density for each cluster (Figure 8). 

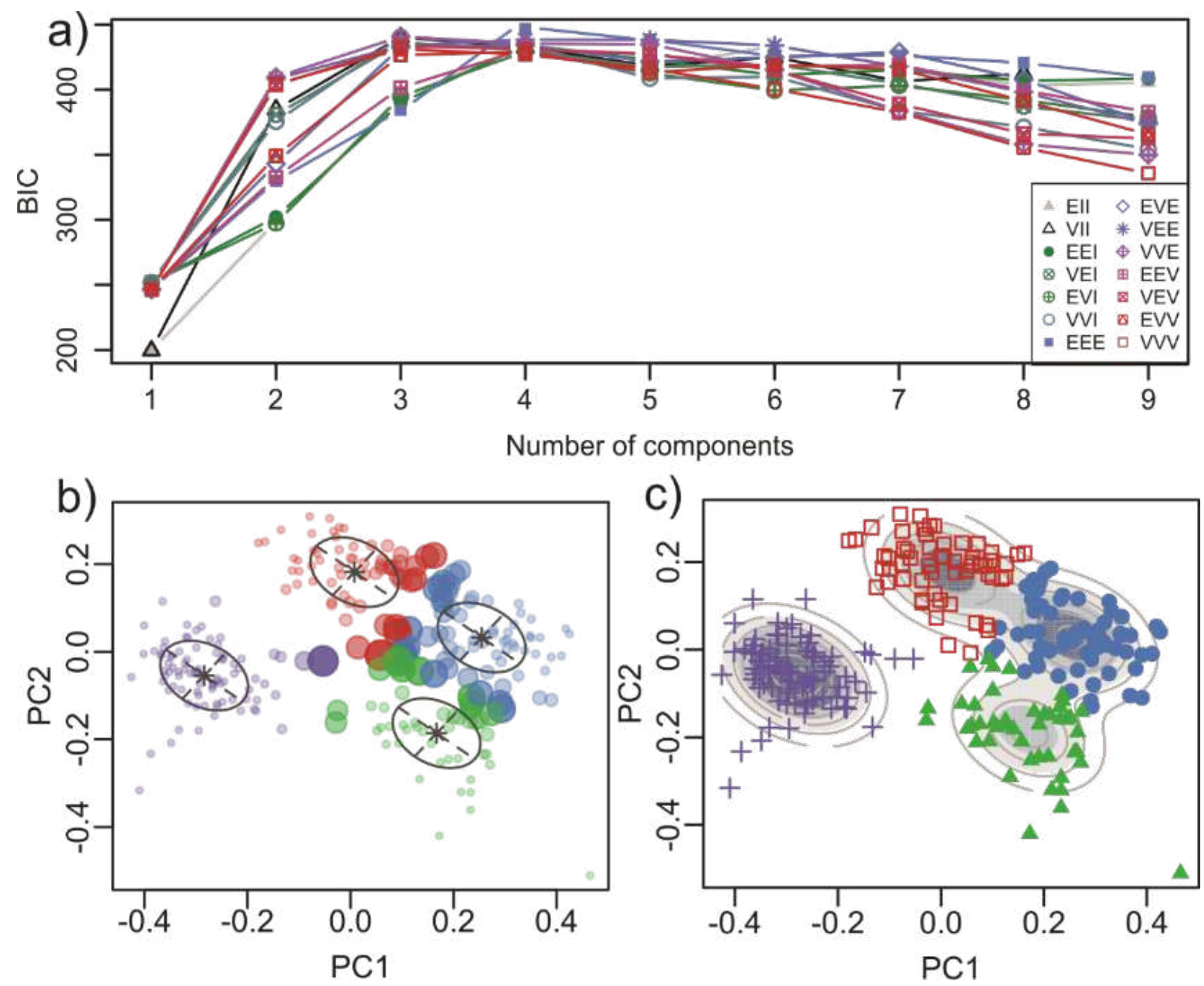

320 Figure 8: a) BIC curve for fourteen statistical models tested. The EEE model shows the first local

321 maximum in 4 components. It means the optimum set is four elliptical equidirectional and equivolume

322 clusters, b) bidimensional plot for the two first principal components for the elliptical models and 323 classified points colored according to the cluster number and with the size of points varying according 324 to the uncertainty for each point, c) classified points in PC1 and PC2 space and probabilistic model for 325 cluster density.

\section{5. Results}

327 Four clustering models were generated in raw data and filtered data, varying according to the

328 clustering method, K-means, or Model-based Clustering (Figure 9).

329 As the K-means Clustering depends on the predefined $k$ parameter given by the maximum

330 Silhouette Average Width (Figure 9a and b), the generated models indicate only two groups by

331 this method (Figure 9a and 8b). Generally, these two groups split those samples with an 
association of $\mathrm{Ni}-\mathrm{Cu}-\mathrm{Cr}$ (negative values of $\mathrm{PC} 1$ ) from those with an association of $\mathrm{Ba}-\mathrm{Zr}$

333 (positive values of PC1).

334 The MBC show some differences in the number of groups between raw and filtered data. Only

335 three clusters were defined on raw data, with a superposition of groups on the space generated

336 by the two first dimensions (Figure 9c). While for the filtered data, four distinct groups with no superposition on PC1-PC2 space were defined (Figure 9d).

338 Moreover, on the pseudo-log generation (in-depth constrained clustering analysis), the effect

339 of filtering becomes more evident as the high-frequency noise tends to decrease in both K-

340 means and MBC pseudo-logs (Figure 10). For all pseudo-logs generated, the MBC ran on

341 filtered data is closer to the manually described log. Furthermore, there are still notable

342 differences, such as an apparent greater detail in the APA2001 drill core (separating a class for

343 the more sulfide range). Besides, no clustering model was able to distinguish between the rocks

344 described as calc-silicate and metamafic.

a) K-Means Cluster (Raw Data)

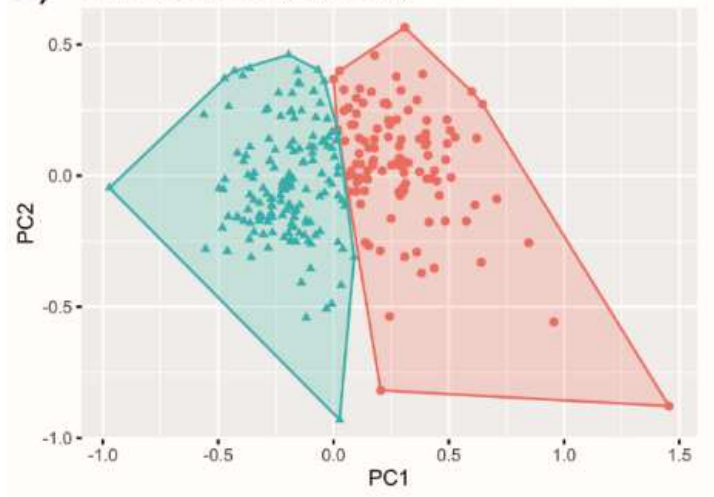

C) MB Cluster (Raw Data)

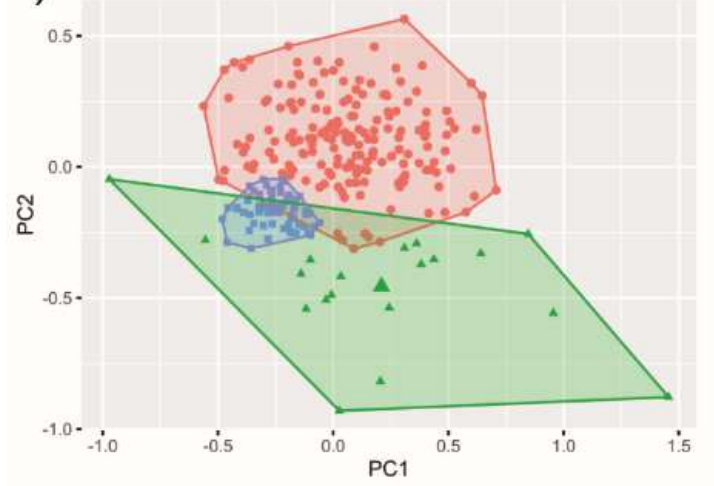

b) K-Means Cluster (Filtered Data)

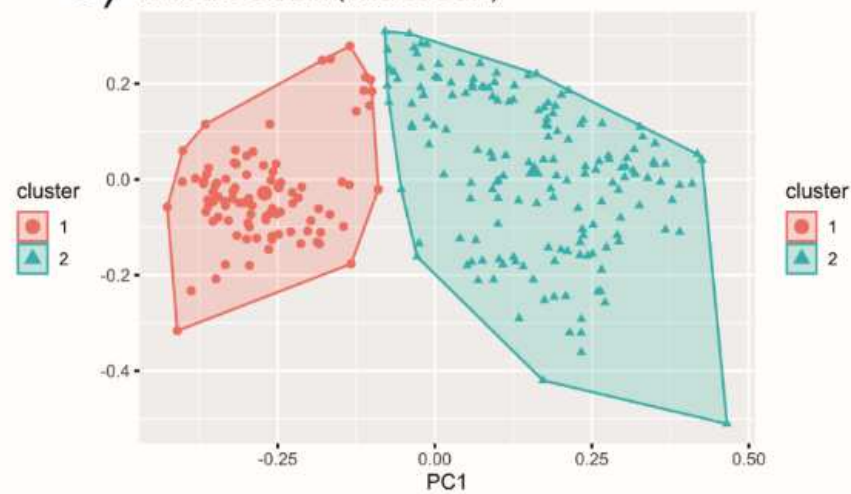

d) MB Cluster (Filtered Data)

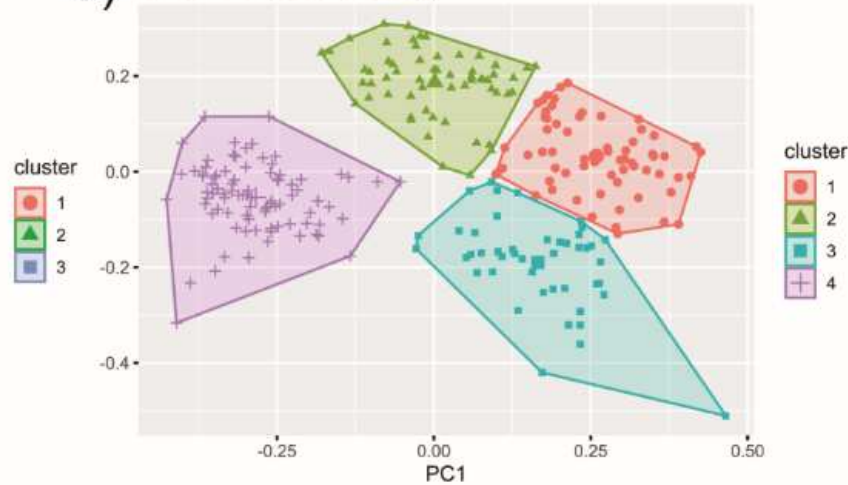


346 Figure 9: Bivariate plot of the first and second dimensions of PCA with each sample's position and the

347 respective cluster classification. K-means for Clustering for a) raw and b) filtered data; $\mathrm{MBC}$ for c) raw 348 and d) filtered data.
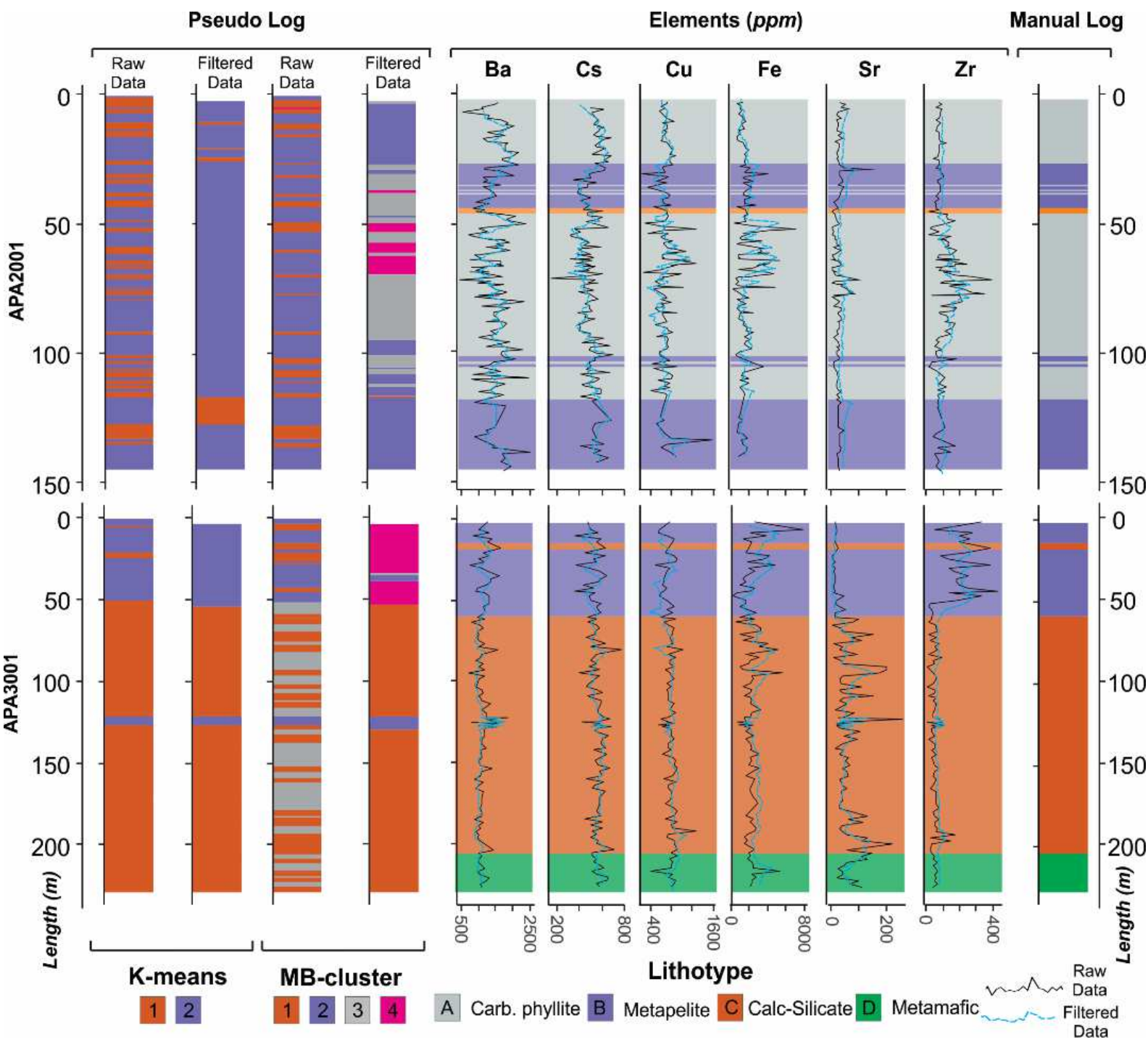

350 Figure 10: Pseudo-log of drill cores APA2001 and APA3001 generated by K-means and MBC for raw

351 and filtered data and comparing element variation and manual log description.

\section{6. Conclusions}

353 We performed two types of Clustering Analysis in portable X-Ray Fluorescence data of drill

354 core samples from a VHMS occurrence hosted in an Archean/Paleoproterozoic greenstone belt:

355 K-means and Model-Based Clustering. Another comparison we tested was models developed

356 over raw and Exponentially Weighted Mean Average filtered data. 
357 The application of a filter to noisy data, such as that found in some $\mathrm{pXRF}$ assays, helps separate 358 groups of lithotypes. As the clustering models rely on geochemical contrast, the filtering 359 process allied to Principal Component Analysis helped increase the signal to noise 360 compensation and maximize the contrast between the clusters. In general, both models 361 developed using the filtered data showed clustering performance closer to that described by 362 professionals.

363 Both the Silhouette and elbow methods suggest only two clusters for the K-means, which 364 vaguely resembles separating the metapelites and calc-silicate rock, but this method could not 365 detect any other lithotypes.

366 On the other hand, the Model-Based Clustering analysis suggested four clusters, resembling 367 more with the manual log description. The model could assess this resemblance even then some 368 key-elements were not available for the analysis, like $\mathrm{C}, \mathrm{Mg}, \mathrm{Ca}$, and $\mathrm{K}$ (some of them not 369 analyzed by the pXRF or not pass in the several data tests ran before the clustering model).

370 In some cases, the pseudo-log models consistently proposed changes on the rock type not 371 detected in the manual log. The method was able to detect small variations in composition amid 372 large rock packages that went unnoticed in the manual description.

373 However, one lithotype described as "metamafic rock" at the bottom of the APA3001 drill core 374 could not be detected by any models. A possible explanation is the lack of contrast between the 375 analyzed elements due to the similar mineralogy confirmed by thin-section petrography.

376 The samples from the core APA2001 have a higher level of difficulty fitting a model because 377 of the thin layers repeating rhythmically, as seen in the manual log description. The core 378 APA3001 is more homogeneous than the former, and even in raw data, the models had a certain 379 degree of convergence.

380 One issue to be considered is the spatial resolution of the measurements. This matter allied to 381 the geochemical contrast can contribute to the pseudo-log's resemblance to the manual 
382 description, and for small resolution as the one taken in this work, only general discrimination 383 is expected.

384 After all, the results suggest that the MBC method had a better performance than the K-means, 385 mainly for the filtered data. The use of the methods described in this work, especially the 386 Model-Based Clustering combined with EWMA and PCA, can be applied as an important tool 387 in the mineral exploration industry. It highlights that its application can be of aid to solve 388 problems during the validation of geological models based on drill hole data.

\section{CRediT author statement}

390 GFS Conceptualization, Investigation, Data Curation, Methodology, Visualization, Writing -

391 Original Draft, Formal analysis, Writing - Review \& Editing. JHL Supervision, Data Curation, 392 Formal analysis, Validation, Writing - Review \& Editing. ADRS Investigation, Writing 393 Original Draft, Validation, Writing - Review \& Editing. CGL: Project Administration

394 Investigation, Writing - Original Draft, Validation, Writing - Review \& Editing. ELK:

395 Investigation, Writing - Review \& Editing. KU: Resources, Data Curation. Writing - Review 396 \& Editing.

\section{Acknowledgments}

398 The authors would like to thank the Geological Survey of Brazil - CPRM, for providing the 399 necessary resources for this research, with mention to the geologists Valter Rodrigues Sobrinho 400 for his assistance with field logistic and sampling and Francisco Ferreira de Campos for help 401 the pXRF managing. Special thanks to the Companhia Baiana de Pesquisa Mineral - CBPM, 402 for allowing the sample collection for this study. GFS would like to thank Marcos Vinícius 403 Ferreira and Iago Sousa Lima Costa for relevant commentaries about the code and manuscript. 404 The data processing was done using several open-source packages from the Tidyverse 405 Collection in the R environment (Wickham, 2014).

406 Funding 
407 This research did not receive any specific grant from funding agencies in the public, 408 commercial, or not-for-profit sectors.

\section{Data Availability}

410 Datasets related to this article can be found at https://github.com/gferrsilva/RioSalitre hosted at

411 Github repository (Silva, 2020). Any commentaries about the code or further collaborations are 412 welcome.

\section{Appendix A. Quality Control}

414 The analytical workflow followed the recommendations of Fisher et al. (2014). At the

415 beginning of every batch analysis, the instrument was configured to read continually for at least

41640 minutes to correct the instrumental drift caused by variations on the cathode temperature

417 (Ida, 2004; Thermo-Scientific, 2013).

418 The reference material RM 180-646 was read between every ten samples (or 20 spot

419 measurement). For elements $\mathrm{Zr}, \mathrm{Sr}, \mathrm{Cu}, \mathrm{Ni}, \mathrm{Fe}$, and $\mathrm{Ti}$, was detected a translational bias higher 420 than $2 \%$ on the measurements of the $\mathrm{RM}$ after the $22^{\text {nd }}$ reading (Figure A.1). We applied a 421 correction factor for the adjustment of the values. The factor is calculated by the relation of the 422 average of the first 22 measures. Then this numeral is divided by the average for the offset 423 values (Table A.1.)

424 Table A.1.: Average concentration for elements with a translational bias higher than $2 \%$ and correction 425 factor

\begin{tabular}{c|r|r|r|r|r|r}
\hline \hline & \multicolumn{6}{c}{ Element } \\
\cline { 2 - 7 } & \multicolumn{1}{c|}{$\mathrm{Zr}$} & \multicolumn{1}{l}{$\mathrm{Sr}$} & $\mathrm{Cu}$ & $\mathrm{Ni}$ & \multicolumn{1}{l}{$\mathrm{Fe}$} & \multicolumn{1}{l}{$\mathrm{Ti}$} \\
\hline \hline $\bar{X}_{(1-21)}$ & 377.15 & 103.22 & 284.46 & 100.56 & 40507.43 & 4141.71 \\
\hline $\bar{X}_{(22-36)}$ & 343.07 & 101.02 & 277.74 & 90.73 & 39482.14 & 3882.05 \\
\hline Correction & 1.099 & 1.022 & 1.024 & 1.108 & 1.026 & 1.067 \\
\hline \hline
\end{tabular}

426 

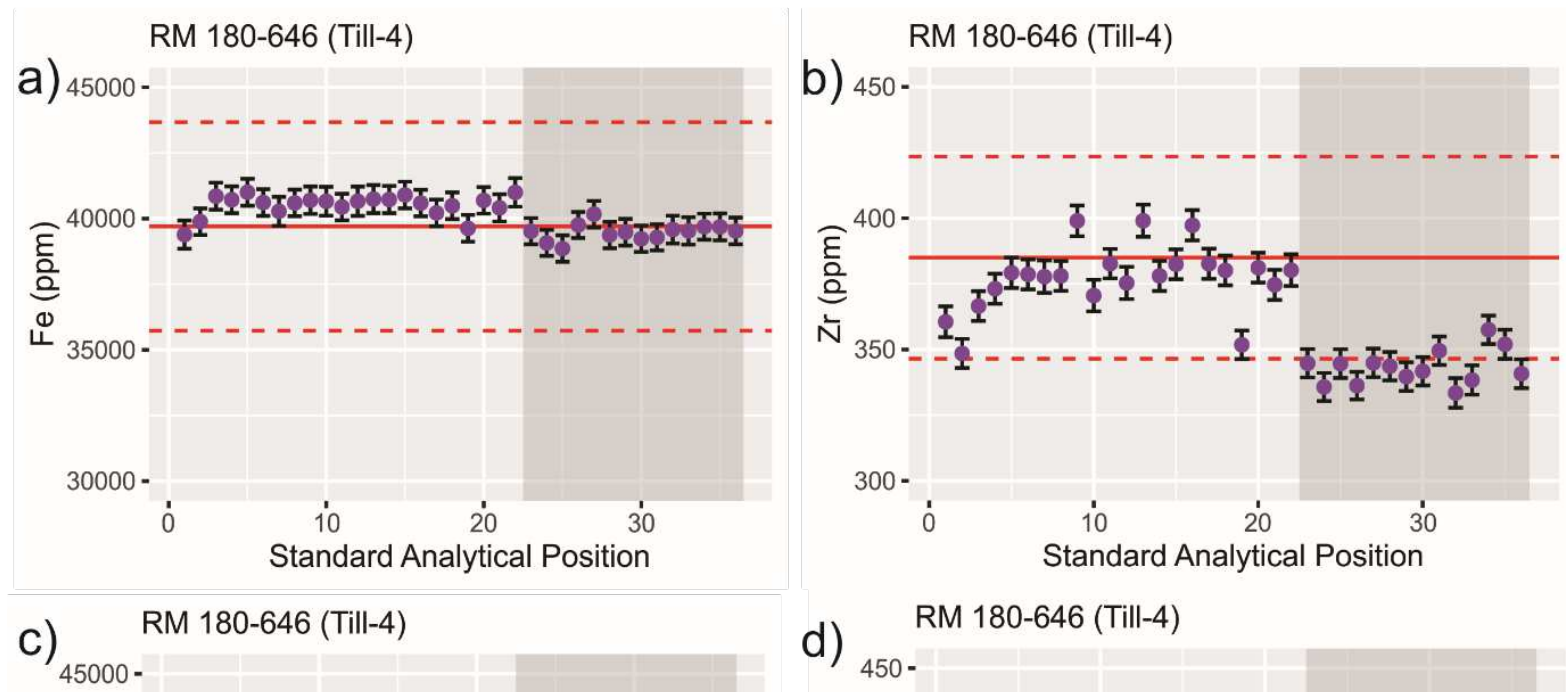

d) ${ }_{450}$ -
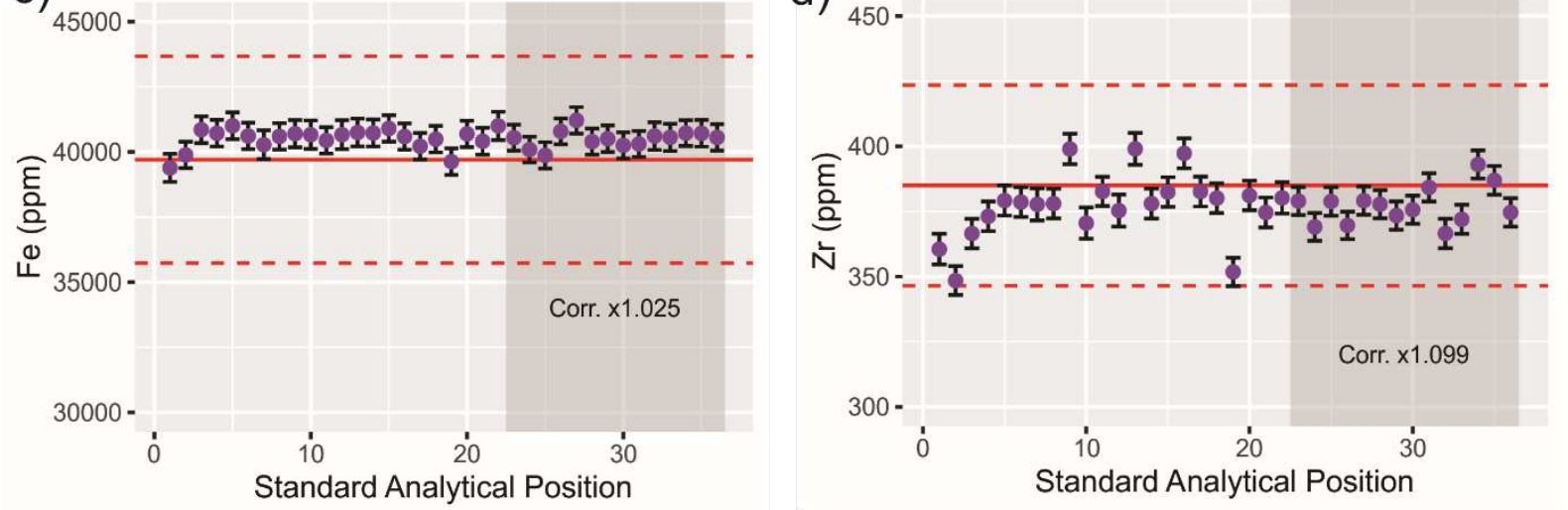

428 Figure A.1.: Shewhart control chart (Piercey, 2014) for measurements on RM 180-646. Identification 429 of the translational bias for a) Fe and b) $\mathrm{Zr}$, and values corrected c) and d) for the same elements.

\section{Appendix B. Significance Tests}

\section{B.1 Verification of Data Distribution}

432 An essential step in exploratory data analysis is the determination of the distribution type. If the 433 data is parametric, the mean and standard deviations are reasonable estimates for the center, 434 and the spread of data and several inference tools can be used to analyze and infer population 435 parameters. Otherwise, data must be treated differently with methods that do not rely on these 436 geometric parameters.

437 There are nearly 40 tests available for normality verification, but several authors (Razali and 438 Wah, 2011; Saculinggan and Balase, 2013; Yap and Sim, 2011) show that the Shapiro-Wilk 439 test is the more powerful test for most types of distributions and sample size. The Shapiro-Wilk 
440 test (Shapiro and Wilk, 1965) was initially defined for small samples $(n<50)$, and then it was

441 improved by Royston (1982) that expanded the test for a greater range of values $(3 \leq n \leq 5000)$.

442 In this work, this test was performed for each selected element on the database, considering

443 only the first pXRF spot data. For a significance level of 5\% and analyzing the P-Value 444 parameter, all the selected elements presented P-Value $<<0.01$ (Table B.1), which means that

445 the respective distribution for each element is not the normal distribution, what can be

446 confirmed in the Q-Q Plot diagram (Figure B.1Figure ).

447 Table B.1: Statistical summary for selected elements with more than $95 \%$ measurements above the lower 448 limit of detection and respective P-Value for the Shapiro-Wilk and Kruskal Wallis Statistical 449 Significance Test

\begin{tabular}{|c|c|c|c|c|c|c|c|c|c|}
\hline \multirow{2}{*}{$\mathrm{N}$} & \multirow{2}{*}{ Element } & \multicolumn{6}{|c|}{ Values (ppm) } & \multicolumn{2}{|c|}{$\begin{array}{l}\text { Statistical Significance: } \\
\text { P-Value }(\alpha=0.05)\end{array}$} \\
\hline & & Min. & 1st Qu. & Median & Mean & 3rd Qu. & Max. & Shapiro-Wilk & Kruskal-Wallis \\
\hline 1 & $\mathrm{Ba}$ & 448.32 & 1069.58 & 1236.66 & 1333.76 & 1592.95 & 2497.94 & $<0.01$ & 0.38 \\
\hline 2 & $\mathrm{Cd}$ & 10.87 & 60.20 & 71.61 & 73.15 & 84.45 & 158.46 & $<0.01$ & 0.57 \\
\hline 3 & $\mathrm{Cl}$ & 1120.56 & 8656.18 & 9432.14 & 9266.63 & 10027.47 & 21456.72 & $<0.01$ & 0.37 \\
\hline 4 & $\mathrm{Cr}$ & 9.17 & 14.06 & 15.54 & 21.66 & 27.82 & 122.06 & $<0.01$ & 0.84 \\
\hline 5 & $\mathrm{Cs}$ & 144.26 & 483.02 & 537.49 & 534.80 & 589.15 & 885.52 & $<0.01$ & 0.05 \\
\hline 6 & $\mathrm{Cu}$ & 249.05 & 644.71 & 731.96 & 731.35 & 812.98 & 1579.56 & $<0.01$ & 0.70 \\
\hline 7 & $\mathrm{Fe}$ & 1905.72 & 11173.17 & 16594.67 & 18730.61 & 23714.21 & 79021.55 & $<0.01$ & 0.33 \\
\hline 8 & $\mathrm{Nd}$ & 335.07 & 634.00 & 785.79 & 783.22 & 918.23 & 1390.39 & $<0.01$ & 0.79 \\
\hline 9 & $\mathrm{Ni}$ & 98.66 & 1398.96 & 1624.67 & 1614.64 & 1865.83 & 3699.80 & $<0.01$ & 0.71 \\
\hline 10 & $\mathrm{P}$ & 1042.74 & 2064.94 & 2316.29 & 2355.65 & 2646.65 & 6825.10 & $<0.01$ & 0.98 \\
\hline 11 & $\operatorname{Pr}$ & 218.89 & 408.59 & 485.02 & 494.92 & 576.88 & 966.06 & $<0.01$ & 0.99 \\
\hline 12 & S & 1712.74 & 5801.68 & 6326.13 & 6805.11 & 6969.70 & 38275.17 & $<0.01$ & 0.42 \\
\hline 13 & $\mathrm{Sb}$ & 37.93 & 180.11 & 209.29 & 210.09 & 236.84 & 383.74 & $<0.01$ & 0.89 \\
\hline 14 & $\mathrm{Si}$ & 12925.20 & 20730.95 & 24491.43 & 27574.16 & 27999.96 & 310304.66 & $<0.01$ & 0.31 \\
\hline 15 & $\mathrm{Sn}$ & 32.08 & 109.56 & 127.64 & 128.42 & 145.10 & 222.73 & $<0.01$ & 0.44 \\
\hline 16 & $\mathrm{Sr}$ & 4.21 & 18.43 & 29.12 & 38.90 & 44.56 & 256.44 & $<0.01$ & 0.79 \\
\hline 17 & $\mathrm{Te}$ & 56.94 & 237.56 & 273.87 & 271.52 & 303.44 & 479.81 & $<0.01$ & 0.13 \\
\hline 18 & $\mathrm{Ti}$ & 5.63 & 43.76 & 63.92 & 81.72 & 91.53 & 4211.33 & $<0.01$ & 0.71 \\
\hline 19 & $\mathrm{~V}$ & 2.18 & 4.24 & 5.25 & 5.71 & 6.37 & 89.51 & $<0.01$ & 0.76 \\
\hline 20 & $\mathrm{Zr}$ & 10.58 & 53.10 & 73.90 & 97.42 & 122.78 & 427.97 & $<0.01$ & 0.97 \\
\hline
\end{tabular}

451 Due to this work's nature, no transformation on data was performed, aiming to force a normal

452 distribution, and we choose to work the data with non-parametric approaches. 


\section{Q-Q plot by element}

$\rightarrow$ 2nd Spot $\rightarrow$ 1st Spot
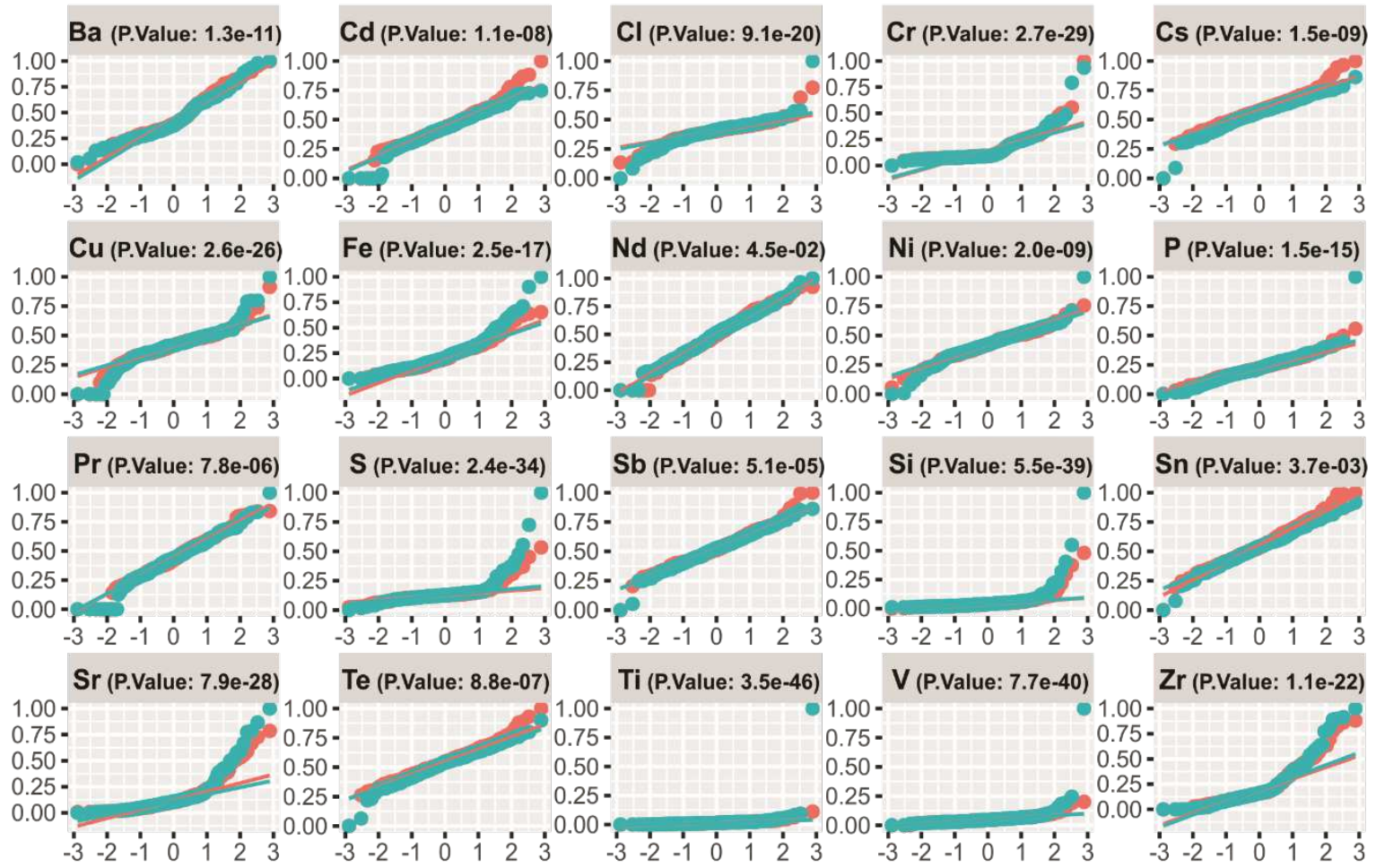

Figure B.1: Q-Q plot for selected elements classified by the distribution of measurements and duplicates

455 with the respective P-Value of the Shapiro-Wilk test of normality.

\section{B.2. Representativity of measurements}

457 The window size of the portable X-Ray Fluorescence can be a struggle point for the analysis,

458 as just a small bit of the rock sample is measured by turn in "point and shoot" mode (Lemière,

459 2018). This fact could lead to taking values that are not representative of the whole sample,

460 even that the rock has small granulation.

461 Regarding this, we ran a double analysis for each sample in different spots to check its statistical

462 representativity. We tested the distributions' statistical equivalence on the two-spot approach

463 by each selected element with the assistance of the Kruskal-Wallis test (KW). KW assess if the

464 distribution of the measurements and duplicates are statistically equivalent (Figure B.2). If it is

465 acceptable that they have an equivalent distribution, we can accept the hypothesis that the data

466 measurements represent that portion of the samples. 
467 The KW test (Kruskal and Wallis, 1952) is an extension of the Wilcox-Mann-Whitney for non468 parametrical data and verifies if the same distribution for ranked values originates two or more

469 independent samples. The KW test is performed for each of the selected elements to check if 470 the first pXRF spot data distribution can be equivalent to the second pXRF spot data 471 distribution. The KW value test is defined as:

$$
K W=(N-1) \frac{\sum_{i=1}^{g} n_{i}\left(\bar{r}_{i .}-\bar{r}\right)^{2}}{\sum_{i=1}^{g} \sum_{j=1}^{n_{i}}\left(\bar{r}_{i j}-\bar{r}\right)^{2}}
$$

473 As $N$ is the total number of analysis for the samples, $n_{i}$ is the number of observations of the $i^{\text {th }}$ 474 group, $r_{i j}$ is the rank of observation $j$ from group $i, \bar{r}$ is the average rank of $r_{i j}$ and $\bar{r}_{i}$ is the 475 average rank of the $i^{\text {th }}$ group.

476 The verification of P-Value assesses the result of the KW for a given $\alpha$ defined as $5 \%$ (Table 477 B.1). Therefore, if P-Value is higher than 0.05 for a given element, it is considered that the 478 distribution of the first pXRF spot can be equivalent to the distribution of the second pXRF 479 spot.

480 All the 20 selected elements have respective P-Value higher than 5\%, and thus are suitable for 481 the modeling. The density distribution for both groups for each element is shown in Figure B.2. 


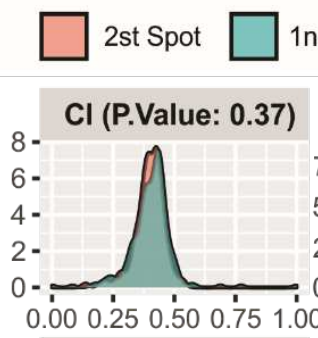
1nd Spot
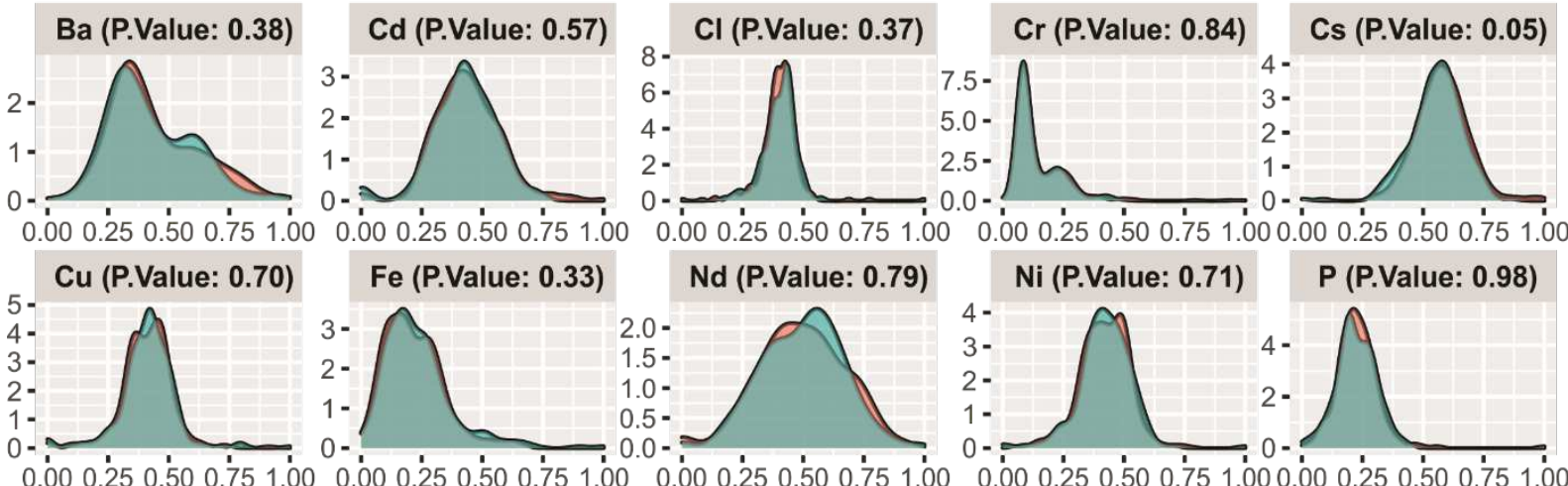

$P$ (P.Value: 0.98)
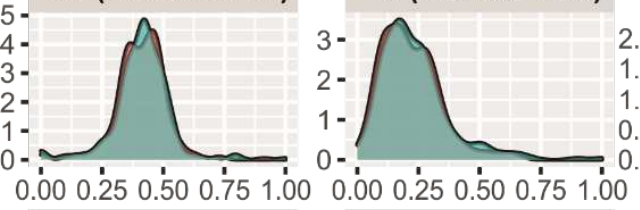

$\operatorname{Pr}$ (P.Value: 0.99)
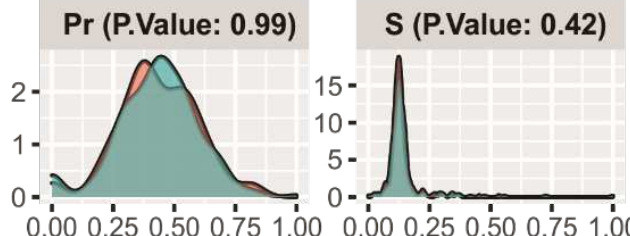

Si (P.Value: 0.31)

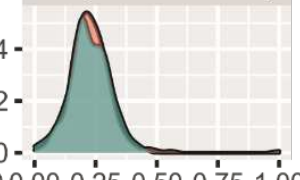

0.000 .250 .500 .751 .00
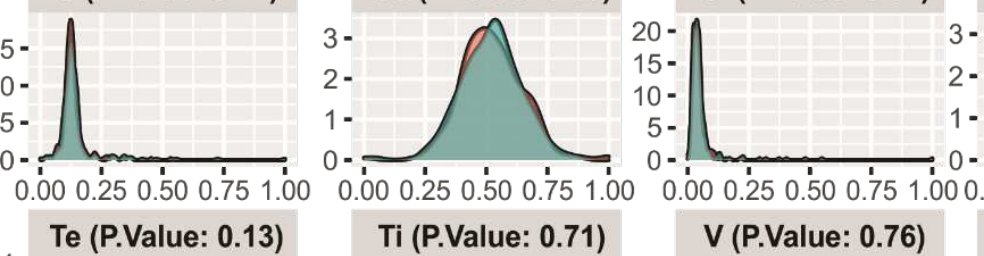

Sn (P.Value: 0.44)
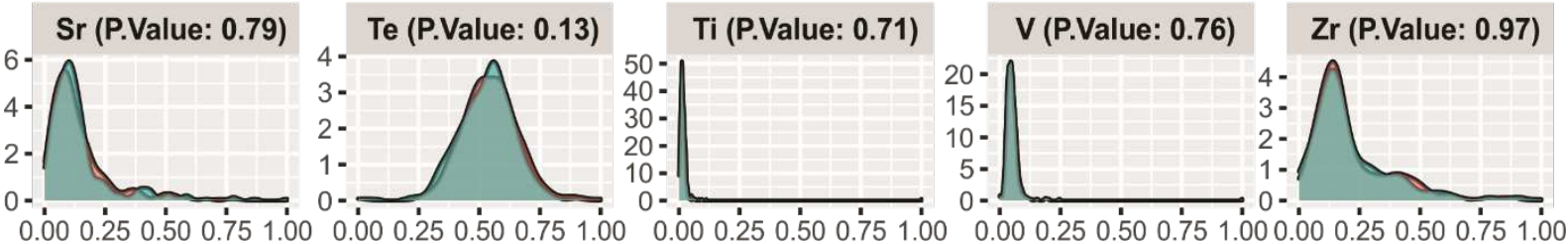

Figure B.2.: Density distribution plot for selected elements classified by the distribution of measurements and duplicates with the respective P-Value of the KW test of equivalence of the two distributions.

\section{REFERENCES}

Alkmim, F.F., Martins-Neto, M.A., 2012. Proterozoic first-order sedimentary sequences of the São Francisco craton, eastern

Brazil. Mar.

Pet. Geol. 33,

$127-139$. https://doi.org/10.1016/j.marpetgeo.2011.08.011

Alkmin, F.F., Brito Neves, B.B., Alves, J.A.C., 1993. Arcabouço tectônico do Cráton do São Francisco: Uma revisão, in: Dominguez, J.M.L., Misi, A. (Eds.), O Cráton Do São Francisco. SBG Sociedade Brasileira de Geociências, Salvador, BA, pp. 45-62.

Angelim, L.A.A., 1997. Petrolina, folha SC.24-V-C: estados da Bahia, Pernambuco e Piauí. Escala 1:250.000. Programa Levantamentos Geológicos Básicos do Brasil - PLGB. CPRM - Companhia de Pesquisa de Recursos Minerais, Brasília, DF.

Barbosa, J.S.., Barbosa, R.G., 2017. The Paleoproterozoic eastern Bahia orogenic domain., in: The São Francisco Craton and Its Margins, Eastern Brazil. Springer-Verlag, pp. 57-69. 
https://doi.org/10.1007/978-3-319-01715-0_4

Barbosa, J.S.., Sabaté, P., 2004. Archean and Paleoproterozoic crust of the São Francisco Craton, Bahia,

$$
\text { Brazil: geodynamic features. Precambrian }
$$

Res.

133

$1-27$.

$501 \quad$ https://doi.org/10.1016/j.precamres.2004.03.001

Barbosa, J.S.F., 2012. Geologia da Bahia: Pesquisa e atualização, 1st ed, Séries e publicações especiais - 13. Companhia Baiana de Pesquisa Mineral, Salvador, BA.

504 Bérubé, C.L., Olivo, G.R., Chouteau, M., Perrouty, S., Shamsipour, P., Enkin, R.J., Morris, W.A., Feltrin, L., Thiémonge, R., 2018. Predicting rock type and detecting hydrothermal alteration using machine learning and petrophysical properties of the Canadian Malartic ore and host rocks, Pontiac Subprovince, Québec, Canada. Ore Geol. Rev. 96, 130-145.

Costa, I., Tavares, F., Oliveira, J., 2019. Predictive lithological mapping through machine learning https://doi.org/10.1016/j.oregeorev.2018.04.011

Boehmke, B., Greenwell, B., 2019. Hands-On Machine Learning with R, 1st ed. Chapman and Hall/CRC. https://doi.org/10.1201/9780367816377

Cordani, U.., Iyer, S.., Taylor, P.., Kawashita, K., Sato, K., McReath, I., 1992. Pb/Pb, Rb/Sr, and K/Ar systematics of the Lagoa Real uranium province (south-central Bahia, Brazil) and the Espinhaço cycle (ca. 1.5-1.0 Ga). J. South Am. Earth Sci. 5, 33-46. https://doi.org/10.1016/0895methods: a case study in the Cinzento Lineament, Carajás Province, Brazil. J. Geol. Surv. Brazil 2, 26-36. https://doi.org/10.29396/jgsb.2019.v2.n1.3

de Almeida, F.F.M., Hasui, Y., de Brito Neves, B.B., Fuck, R.A., 1981. Brazilian structural provinces: An introduction. Earth-Science Rev. 17, 1-29. https://doi.org/10.1016/0012-8252(81)90003-9

Farnham, I.M., Singh, A.K., Stetzenbach, K.J., Johannesson, K.H., 2002. Treatment of nondetects in multivariate analysis of groundwater geochemistry data. Chemom. Intell. Lab. Syst. 60, 265-281. https://doi.org/10.1016/S0169-7439(01)00201-5

Fisher, L., Gazley, M.F., Baensch, A., Barnes, S.J., Cleverley, J., Duclaux, G., 2014. Resolution of geochemical and lithostratigraphic complexity: A workflow for application of portable X-ray 
fluorescence to mineral exploration. Geochemistry Explor. Environ. Anal. 14, 149-159. https://doi.org/10.1144/geochem2012-158

527 Forkman, J., Josse, J., Piepho, H., 2019. Hypothesis Tests for Principal Component Analysis When Variables are Standardized. J. Agric. Biol. Environ. Stat. 24, 289-308. https://doi.org/10.1007/s13253-019-00355-5

Fraley, C., Raftery, A.E., 2002. Model-Based Clustering, Discriminant Analysis, and Density Estimation. J. Am. Stat. Assoc. 97, 611-631. https://doi.org/10.1198/016214502760047131

Fraley, C., Raftery, A.E., 1998. How Many Clusters? Which Clustering Method? Answers Via ModelBased Cluster Analysis 1. Seattle, WA.

534 Frey, B.J., Dueck, D., 2007. Clustering by passing messages between data points. Science (80-. ). 315, 972-976. https://doi.org/10.1126/science.1136800

Garcia, P.M.P., 2017. A Província Cuprífera Do Nordeste Meridional: Evolução Dos Processos E Modelos a Província Cuprífera Do Nordeste Meridional: Evolução Dos Processos E Modelos. UFBA - Universidade Federal da Bahia.

Grunsky, E.C., 2010. The interpretation of geochemical survey data. Geochemistry Explor. Environ. Anal. 10, 27-74. https://doi.org/10.1144/1467-7873/09-210

541 Grunsky, E.C., Arne, D., 2020. Mineral-Resource Prediction Using Advanced Data Analytics and Machine Learning of the QUEST-South Stream-Sediment Geochemical Data, Southwestern British Columbia ( Parts of NTS 082, 092 ), in: Geoscience BC Summary of Acitivities 2019: Minerals, Geoscience BC, Report 2020-01. Geoscience BC, Vancouver, BC, pp. 55-76.

Heilbron, M., Cordani, U.G., Alkmim, F.F., 2017. São Francisco Craton, Eastern Brazil: Tectonic Genealogy of a Miniature Continent. Springer 326. https://doi.org/10.1007/978-3-319-01715-0

Hill, E.J., Pearce, M.A., Stromberg, J.M., 2020. Improving Automated Geological Logging of Drill Holes by Incorporating Multiscale Spatial Methods. Math. Geosci. https://doi.org/10.1007/s11004-020-09859-0

Hill, E.J., Uvarova, Y., 2018. Identifying the nature of lithogeochemical boundaries in drill holes. J. Geochemical Explor. 184, 167-178. https://doi.org/10.1016/j.gexplo.2017.10.023 
Ida, H., 2004. X-ray fluorescence analysis with portable instruments. Kyoto University.

553 Kruskal, W.H., Wallis, W.A., 1952. Use of Ranks in One-Criterion Variance Analysis. J. Am. Stat. Assoc. 47, 583-621. https://doi.org/10.1080/01621459.1952.10483441

Kuhn, S., Cracknell, M.J., Reading, A.M., 2018. Lithologic mapping using Random Forests applied to geophysical and remote-sensing data: A demonstration study from the Eastern Goldfields of Australia. GEOPHYSICS 83, B183-B193. https://doi.org/10.1190/geo2017-0590.1

Kwak, S.K., Kim, J.H., 2017. Statistical data preparation: Management of missing values and outliers. Korean J. Anesthesiol. https://doi.org/10.4097/kjae.2017.70.4.407

Lai, K., Twine, N., O’Brien, A., Guo, Y., Bauer, D., 2018. Artificial intelligence and machine learning in bioinformatics. Encycl. Bioinforma. Comput. Biol. ABC Bioinforma. 1-3, 272-286. https://doi.org/https://doi.org/10.1016/B978-0-12-809633-8.20325-7

Landau, S., Chis Ster, I., 2010. Cluster Analysis: Overview, in: International Encyclopedia of Education.

$$
\text { Elsevier, pp. 72-83. https://doi.org/10.1016/B978-0-08-044894-7.01315-4 }
$$

Le Vaillant, M., Barnes, S.J., Fisher, L., Fiorentini, M.L., Caruso, S., 2014. Use and calibration of

Lemière, B., 2018. A review of pXRF (field portable X-ray fluorescence) applications for applied geochemistry.

J. Geochemical Explor.

188 , $350-363$. https://doi.org/10.1016/j.gexplo.2018.02.006

Lengyel, A., Botta-Dukát, Z., 2019. Silhouette width using generalized mean-A flexible method for assessing clustering efficiency. Ecol. Evol. 9, 13231-13243. https://doi.org/10.1002/ece3.5774

Lloyd, S.P., 1982. Least Squares Quantization in PCM. IEEE Trans. Inf. Theory 28, 129-137. https://doi.org/10.1109/TIT.1982.1056489

Lucas, A., Zhang, X., 2016. Score-driven exponentially weighted moving averages and Value-at-Risk forecasting. Int. J. Forecast. 32, 293-302. https://doi.org/10.1016/j.ijforecast.2015.09.003 
control chart to monitor the process mean. Eur. J. Oper. Res. 279, 902-911. https://doi.org/10.1016/j.ejor.2019.07.002

Mouton, J.P., Ferreira, M., Helberg, A.S.J., 2020. A comparison of clustering algorithms for automatic modulation classification. Expert Syst. Appl. 113317. https://doi.org/10.1016/j.eswa.2020.113317

Nakano, M., Takahashi, A., Takahashi, S., 2017. Generalized exponential moving average (EMA) model with particle filtering and anomaly detection. Expert Syst. Appl. 73, 187-200. https://doi.org/10.1016/j.eswa.2016.12.034

Oliveira, E.P., Windley, B.F., Araújo, M.N.C., 2010. The Neoproterozoic Sergipano orogenic belt, NE Brazil: A complete plate tectonic cycle in western Gondwana. Precambrian Res. 181, 64-84. https://doi.org/10.1016/j.precamres.2010.05.014

Piercey, S.J., 2014. Modern analytical facilities 2. A review of quality assurance and quality control (qa/qc) procedures for lithogeochemical data. Geosci. Canada 41, 75-88. https://doi.org/10.12789/geocanj.2014.41.035

Razali, N.M., Wah, Y.B., 2011. Power comparisons of Shapiro-Wilk, Kolmogorov-Smirnov, Lilliefors and Anderson-Darling tests. J. Stat. Model. Anal. 2, 21-33.

Ribeiro, A.F., Garrido, I.A., Brito, R.S.C., Nonato, I.F., 1993. Geologia e potencialidade para mineralizações de ouro e sulfetos da Faixa Rio Salitre, Juazeiro - Bahia. Série Arquivos Abertos. CBPM - Companhia Baiana de Pesquisa Mineral, Salvador, BA.

Rodriguez-galiano, V., Sanchez-castillo, M., Chica-olmo, M., Chica-rivas, M., 2015. Machine learning 604 Royston, J.P., 1982. An Extension of Shapiro and Wilk’s W Test for Normality to Large Samples. Appl. predictive models for mineral prospectivity : An evaluation of neural networks, random forest, regression trees and support vector machines. Ore Geol. Rev. 71, 804-818. https://doi.org/10.1016/j.oregeorev.2015.01.001

Ross, G.J., Adams, N.M., Tasoulis, D.K., Hand, D.J., 2012. Exponentially weighted moving average charts for detecting concept drift. Pattern Recognit. Lett. 33, 191-198. https://doi.org/10.1016/j.patrec.2011.08.019

Stat. 31, 115-124. https://doi.org/10.2307/2347973 
606 Saculinggan, M., Balase, E.A., 2013. Empirical power comparison of goodness of fit tests for normality

607 in the presence of outliers. J. Phys. Conf. Ser. 435. https://doi.org/10.1088/1742$608 \quad 6596 / 435 / 1 / 012041$

609 Shapiro, S.S., Wilk, M.B., 1965. An analysis of variance test for normality (complete samples).

610 Biometrika 52, 591-611. https://doi.org/10.1093/biomet/52.3-4.591

611 [dataset] Silva, G.F. da, 2020. Model-Based Clustering for unsupervised drill core pseudo-log

612 generation - Repository [WWW Document]. Github. URL https://github.com/gferrsilva/RioSalitre $613 \quad$ (accessed 9.16.20).

614 Teixeira, W., Carneiro, M.A., Noce, C.M., Machado, N., Sato, K., Taylor, P.N., 1996. Pb, Sr and Nd 615 isotope constraints on the Archaean evolution of gneissic-granitoid complexes in the southern São 616 Francisco Craton, Brazil. Precambrian Res. 78, 151-164. https://doi.org/10.1016/0301$617 \quad 9268(95) 00075-5$

618 Teixeira, W., Oliveira, E.P., Marques, L.S., 2017. Nature and evolution of the Archean crust of the São 619 Francisco Craton, in: Heilbron, M., Alkmin, F.F., Cordani, U.G. (Eds.), The São Francisco Craton 620 and Its Margins, Eastern Brazil. Springer-Verlag, pp. 29-56.

621 Thermo-Scientific, 2013. Mining and exploration: Solutions from early-stage discovery through mineral 622 processing. San Jose, California.

623 Wedge, D., Hartley, O., McMickan, A., Green, T., Holden, E.J., 2019. Machine learning assisted 624 geological interpretation of drillhole data: Examples from the Pilbara Region, Western Australia. Ore Geol. Rev. 114, 103118. https://doi.org/10.1016/j.oregeorev.2019.103118

626 Wickham, H., 2016. ggplot2, Use R! Springer International Publishing, Cham. 627 https://doi.org/10.1007/978-3-319-24277-4

628 Wickham, H., 2014. Tidy Data. J. Stat. Softw. 59. https://doi.org/10.18637/jss.v059.i10

629 Yap, B.W., Sim, C.H., 2011. Comparisons of various types of normality tests. J. Stat. Comput. Simul. $630 \quad 81,2141-2155$. https://doi.org/10.1080/00949655.2010.520163

631 